\title{
Ocean heat content variability and change in an ensemble of ocean reanalyses
}

\author{
M. D. Palmer ${ }^{1}$ C. D. Roberts ${ }^{1} \cdot$ M. Balmaseda ${ }^{2} \cdot$ Y.-S. Chang ${ }^{3} \cdot$ G. Chepurin ${ }^{4}$ '

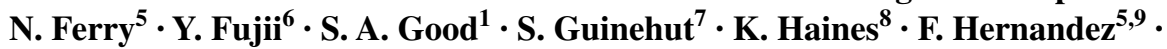 \\ A. Köhl ${ }^{10} \cdot$ T. Lee ${ }^{11}$ - M. J. Martin ${ }^{1}$ - S. Masina ${ }^{12,13} \cdot$ S. Masuda $^{14}$ - K. A. Peterson ${ }^{1}$

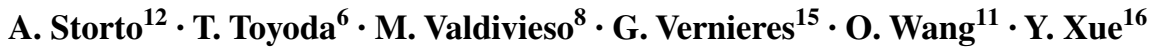

Received: 23 February 2015 / Accepted: 12 August 2015 / Published online: 4 September 2015

(C) The Author(s) 2015. This article is published with open access at Springerlink.com

\begin{abstract}
Accurate knowledge of the location and magnitude of ocean heat content (OHC) variability and change is essential for understanding the processes that govern decadal variations in surface temperature, quantifying changes in the planetary energy budget, and developing constraints on the transient climate response to external forcings. We present an overview of the temporal and spatial characteristics of $\mathrm{OHC}$ variability and change as represented by an ensemble of dynamical and statistical ocean reanalyses (ORAs). Spatial maps of the 0-300 m layer show large
\end{abstract}

This paper is a contribution to the special issue on Ocean estimation from an ensemble of global ocean reanalyses, consisting of papers from the Ocean Reanalyses Intercomparsion Project (ORAIP), coordinated by CLIVAR-GSOP and GODAE OceanView. The special issue also contains specific studies using single reanalysis systems.

M. D. Palmer

matthew.palmer@metoffice.gov.uk

1 Met Office Hadley Centre, Exeter, UK

2 European Centre for Medium-Range Weather Forecasting (ECMWF), Reading, UK

3 Geophysical Fluid Dynamics Laboratory (GFDL), Princeton University, Princeton, NJ, USA

4 University of Maryland, College Park, MD, USA

5 Mercator Océan, Ramonville Saint Agne, France

6 Meteorological Research Institute (MRI), Japan Meteorological Agency, Tsukuba, Japan

7 CLS Space Oceanography Division, Ramonville Saint Agne, France

8 University of Reading, Reading, UK

9 Institut de Recherche pour le Développement (IRD), Toulouse, France regions of the Pacific and Indian Oceans where the interannual variability of the ensemble mean exceeds ensemble spread, indicating that $\mathrm{OHC}$ variations are well-constrained by the available observations over the period 1993-2009. At deeper levels, the ORAs are less well-constrained by observations with the largest differences across the ensemble mostly associated with areas of high eddy kinetic energy, such as the Southern Ocean and boundary current regions. Spatial patterns of $\mathrm{OHC}$ change for the period 1997-2009 show good agreement in the upper $300 \mathrm{~m}$ and are characterized by a strong dipole pattern in the Pacific Ocean. There is less agreement in the patterns of change at deeper levels, potentially linked to differences in the representation of ocean dynamics, such as water mass formation processes. However, the Atlantic and Southern Oceans

10 University of Hamburg, Hamburg, Germany

11 Jet Propulsion Laboratory, California Institute of Technology, Pasadena, CA, USA

12 Centro Euro-Mediterraneo sui Cambiamenti Climatici (CMCC), Bologna, Italy

13 Istituto Nazionale di Geofisica e Vulcanologia (INGV), Bologna, Italy

14 Research and Development Center for Global Change, Japan Agency for Marine-Earth Science and Technology, Yokosuka, Japan

15 Global Ocean and Assimilation Office (GMAO), NASA, Washington, DC, USA

16 NCEP/NOAA Climate Prediction Center, College Park, MD, USA 
are regions in which many ORAs show widespread warming below $700 \mathrm{~m}$ over the period 1997-2009. Annual time series of global and hemispheric OHC change for 0-700 m show the largest spread for the data sparse Southern Hemisphere and a number of ORAs seem to be subject to large initialization 'shock' over the first few years. In agreement with previous studies, a number of ORAs exhibit enhanced ocean heat uptake below 300 and $700 \mathrm{~m}$ during the mid1990 s or early 2000 s. The ORA ensemble mean ( \pm 1 standard deviation) of rolling 5-year trends in full-depth $\mathrm{OHC}$ shows a relatively steady heat uptake of approximately $0.9 \pm 0.8 \mathrm{~W} \mathrm{~m}^{-2}$ (expressed relative to Earth's surface area) between 1995 and 2002, which reduces to about $0.2 \pm 0.6 \mathrm{~W} \mathrm{~m}^{-2}$ between 2004 and 2006, in qualitative agreement with recent analysis of Earth's energy imbalance. There is a marked reduction in the ensemble spread of OHC trends below $300 \mathrm{~m}$ as the Argo profiling float observations become available in the early 2000s. In general, we suggest that ORAs should be treated with caution when employed to understand past ocean warming trends-especially when considering the deeper ocean where there is little in the way of observational constraints. The current work emphasizes the need to better observe the deep ocean, both for providing observational constraints for future ocean state estimation efforts and also to develop improved models and data assimilation methods.

Keywords Heat content - Temperature - Variability · Climate change $\cdot$ Global warming $\cdot$ Energy budget $\cdot$ Ocean reanalyses - Ocean state estimation - Ocean models $\cdot$ Inter comparison $\cdot$ Ocean $\cdot$ Observations $\cdot$ Data assimilation

\section{Introduction}

Ocean reanalyses (ORAs) represent an important tool for understanding ocean variability and climate change (Lee et al. 2009) and underpin a number of forecast activities, such as operational oceanography and seasonal-to-decadal prediction (Rienecker et al. 2010). ORAs employ a variety of ocean general circulation models (OGCMs) and data assimilation schemes to synthesize a diverse network of available ocean observations in order to arrive at a dynamically consistent estimate of the historical ocean state. The nature of the underlying OGCM, data assimilation scheme and observations used varies, often according to the role for which the ORA is intended. For example, systems designed for near real-time forecasts of the ocean mesoscale tend to use higher resolution OGCMs and satellite altimeter data will feature strongly in the assimilation system. Conversely, systems that are used primarily for estimating the ocean state over the 20th Century will tend to use coarser resolution OGCMs and/or simpler assimilation schemes for reasons of computational expense. In addition, a number of products combine the available observations into spatiallycomplete gridded fields using purely statistical approaches, without the use of an OGCM.

Intercomparison of ORAs promotes insights into the performance of data assimilation systems, the underlying physical models, and adequacy of the ocean observing system to constrain key variables of interest, such as ocean heat content change (e.g. Carton and Santorelli 2008; Xue et al. 2012). Here we present a comparison of a number of state-of-the-art products as part of the Ocean Reanalysis Intercomparison Project (ORA-IP; Balmaseda et al. 2015), which is an international research collaboration led by the CLIVAR Global Synthesis and Observations Panel (GSOP) and the Global Ocean Data Assimilation Experiment (GODAE) community. The scope of ORA-IP includes various aspects of the ocean state, including the following: sea level; mixed layer depth; ocean salinity; surface fluxes and mass; heat and freshwater transports. The present work focuses on the representation of OHC variability and change as represented by an ensemble of ORAs (Table 1).

$\mathrm{OHC}$ is a key variable for initialization of seasonalto-decadal predictions (Balmaseda et al. 2010; Dunstone and Smith 2010) and the rate of ocean heat uptake under anthropogenic climate change plays an important part in determining future global surface temperature and sea level rise (Kuhlbrodt and Gregory 2012). Improved understanding the processes that control $\mathrm{OHC}$ variability and change may offer the potential to reduce uncertainties in future climate change projections through application of suitable observational constraints (e.g. Stott and Forest 2007). Thus ORAs have an important role to play in development of improved forecasts on a range of timescales and in refining our understanding of future global and regional climate change.

OHC variability and change is a particularly topical research area, given the strong scientific and wider media interest in the recent slowdown in surface temperature rise (e.g. Hawkins et al. 2014), often referred to as the global warming 'hiatus' (e.g. Trenberth and Fasullo 2013). Increased ocean heat uptake and the vertical re-arrangement of heat in the ocean have both been proposed as key mechanisms that have contributed to the 'hiatus'. Heat rearrangement has been linked primarily with the tropical Pacific (Meehl et al. 2011; England et al. 2014) but there is evidence that the higher latitudes may also have played a role (Chen and Tung 2014; Drijfhout et al. 2014; Roemmich et al. 2015).

ORAs provide an important resource for improving our understanding of the ocean's role in modulating global surface temperature rise on interannual to decadal timescales. Analysis of climate model simulations has shown substantial vertical re-arrangement of ocean heat and highlighted 


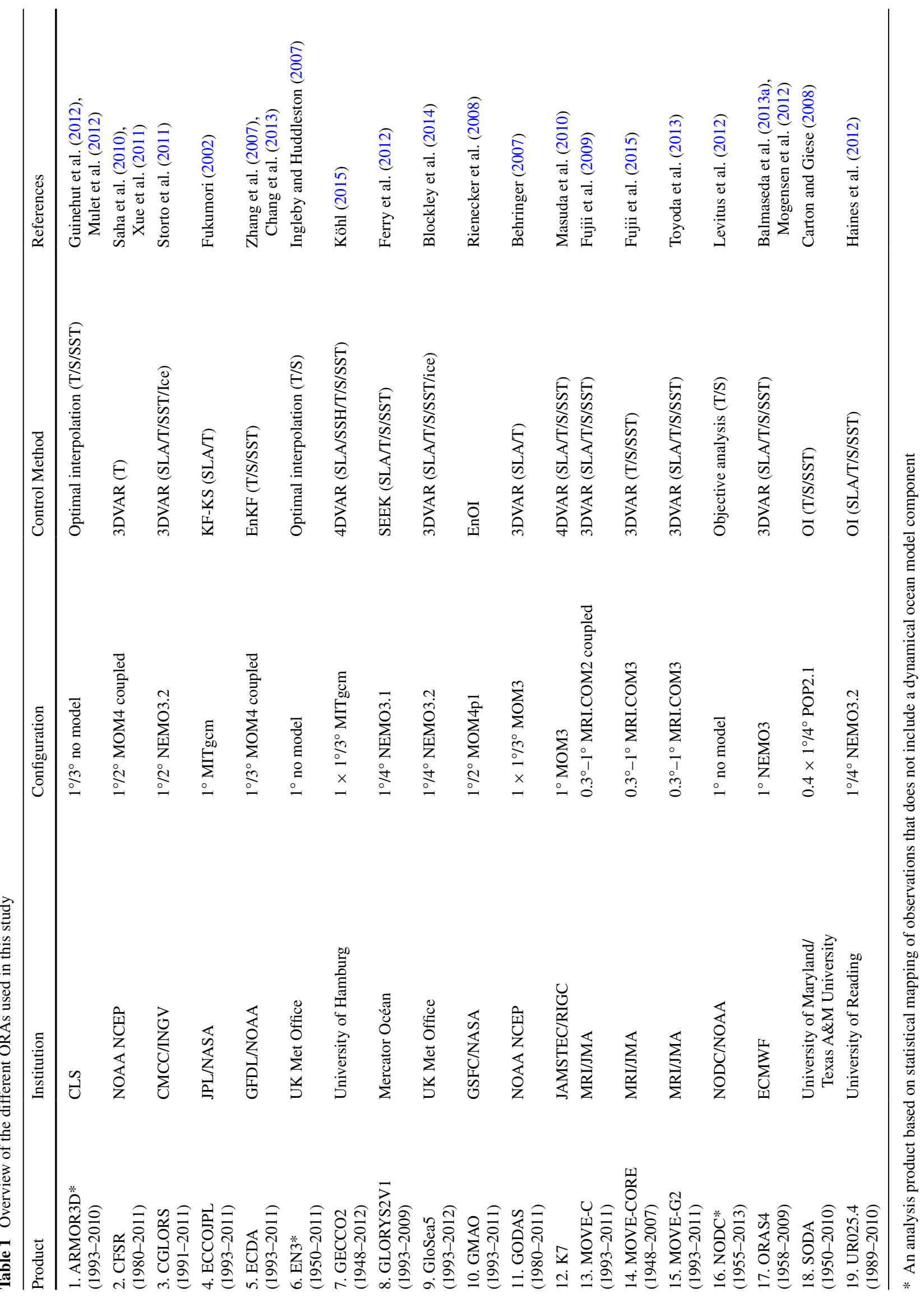


the global ocean's dominant role in Earth's energy budget on annual-to-decadal timescales (Palmer et al. 2011; Palmer and McNeall 2014). Through combining the available ocean observations with OGCMs, ORAs may offer new insights into the processes of vertical heat re-arrangement and have also be used to derive estimates of Earth's energy imbalance (Loeb et al. 2012; Trenberth et al. 2014; Smith et al. 2015).

Despite the recent development of the Argo network of profiling floats (Roemmich et al. 2009), historical observations of ocean temperature are sparse in time and space (Purkey and Johnson 2010; Desbruyères et al. 2014), often limited to a particular depth range, and may require correction for instrumental biases (Abraham et al. 2013). These issues mean that there are substantial-and difficult to quantify-uncertainties in our knowledge of ocean heat content change during the late twentieth and early twenty first centuries. One way to evaluate this uncertainty is using the spread of different reanalysis products that use ostensibly the same raw information, but different methodologies, to evaluate the same variable of interest. Previous studies have used similar 'ensembles of opportunity' to characterize the uncertainty in upper ocean heat content derived from statistical analyses (Lyman et al. 2010; Palmer et al. 2010; Abraham et al. 2013).

Estimates of the past ocean state are fundamentally limited by the availability of historical ocean profiles. Prior to the inception of the Argo array profiling floats in the early 2000s, reasonable ocean coverage is only afforded for the upper few hundred meters since the late 1960s (Roemmich et al. 2012; Lyman and Johnson 2014). As a result, many of the historical estimates of OHC variability and change have been limited to the upper $700 \mathrm{~m}$ or so (Lyman et al. 2010; Palmer et al. 2010; Abraham et al. 2013). In addition, the upper layers of the ocean are widely regarded to be the primary source of predictability for seasonal forecast systems, for example for initializing the tropical Pacific for ENSO forecasts (Xue et al. 2012). For these reasons, much of our analysis focuses ocean depth $\leq 700 \mathrm{~m}$.

We present spatial patterns of depth-integrated temperature for the following: (i) the climatological time mean; (ii) the amplitude of the seasonal cycle; (iii) internannual variability; (iv) decadal and multi-decadal trends. We also compare zonal averages of (i) and (ii). The manuscript is organized as follows. In Sect. 2 we present an overview of the ORA datasets used. The pre-processing steps and analysis methods are presented in Sect. 3. The results are presented in Sects. 4-7 and cover the following aspects: the timemean $\mathrm{OHC}$ and seasonal cycle; interannual variability; time series of $\mathrm{OHC}$; and spatial trends of OHC. In Sect. 8 we present our closing discussion and summary.

\section{Data}

A total of 19 ORAs are used in the intercomparison presented here. These span a range of time periods and have a diverse set of data assimilation methods and underlying ocean model configurations (Table 1). While the majority of products include a dynamic OGCM, three of the products are based on statistical analysis of the observations (ARMOR3D, EN3 and NODC) and do not include a dynamic model component. Note that the ARMOR3D product only covers the upper $2000 \mathrm{~m}$. For the purposes of this intercomparison the deeper levels use the NODC climatology and therefore the variability and change signals below $2000 \mathrm{~m}$ for ARMOR3D are very small, by construction. We use a version of the EN3 analysis that is based on profiles with expendable bathythermograph (XBT) corrections applied following table 1 of Wijffels et al. (2008). The NODC data have mechanical baythermograph (MBT) and XBT bias corrections applied as described in Levitus et al. (2012). All data providers carried out the computation of vertically-integrated temperature for a number of vertical layers (see Sect. 3) and interpolated the data onto a regular $1 \times 1$ degree latitude-longitude grid. To ensure consistency among the grids used, all data were subsequently post-processed using the Climate Data Operator bilinear remapping tool.

\section{Methods}

For the purposes of this intercomparison, the different production centers provided monthly-mean two-dimensional fields of depth-integrated potential temperature, $\langle\theta\rangle$, from the surface to a number of fixed depths, defined as:

$\langle\theta\rangle=\int \theta(\mathrm{x}, \mathrm{y}, \mathrm{z}) \mathrm{dz}$

with units Celsius meters $(\mathrm{Cm})$. Throughout much of the manuscript we use depth integrated temperature as basis of the intercomparison. An advantage of $\langle\theta\rangle$ is that it has an intuitive physical interpretation. For example, a change in $\langle\theta\rangle$ of $70 \mathrm{Cm}$ over the $0-700 \mathrm{~m}$ layer is equivalent to a $0.1 \mathrm{C}$ average change over the column. Annual time series of $\mathrm{OHC}$ are generated for each hemisphere and the globe by spatially integrating maps of $\langle\theta\rangle$ and multiplying by reference values of seawater density $\left(1025 \mathrm{~kg} \mathrm{~m}^{-3}\right)$ and specific heat capacity $\left(3985 \mathrm{~J} \mathrm{~kg}^{-1} \mathrm{~K}^{-1}\right)$. These time series are converted to $\mathrm{OHC}$ anomalies by subtracting the mean value over a reference period. The integration depths specified for the intercomparison were: 0-100 m; 0-300 m; 0-700 m; 0-1500 m; 0-3000 m;0-4000 m; and the full water column (0-bottom). For some products the closest model level was 
used for the integration, provided that this was within a few meters of the specified depth. The data are analyzed as a 'true' integral, meaning that the summation is inclusive of all ocean model grid boxes shallower than the lower bound of the integration. Thus the number of ocean grid points for each product is the same for all layer integrals and, for example, the 300-700 $\mathrm{m}$ layer can be reconstructed by simply subtracting the 0-300 $\mathrm{m}$ layer from the $0-700 \mathrm{~m}$ layer.
Monthly climatologies for each product are computed for the period 1993-2009, with the exception of MOVECORE (see Sect. 2), for which we use the period 1993-2007. These climatologies are used in two aspects of the intercomparison. Firstly, the time-average for each grid box is computed to provide a comparison of the mean state of the period 1993-2009. Secondly, the amplitude of the climatological seasonal cycle is computed for each grid
Fig. 1 Anomaly of climatological depth-integrated temperature for the $0-700 \mathrm{~m}$ layer (Celsius meters) for each ORA relative to the ensemble mean. Also shown is the ensemble mean, standard deviation and signalto-noise ratio. All values are computed for the period 1993 2009, except for MOVECORE (1993-2007)

\section{$0-700 \mathrm{~m} \mathrm{OHC} \mathrm{in} \mathrm{ocean} \mathrm{analyses}$}
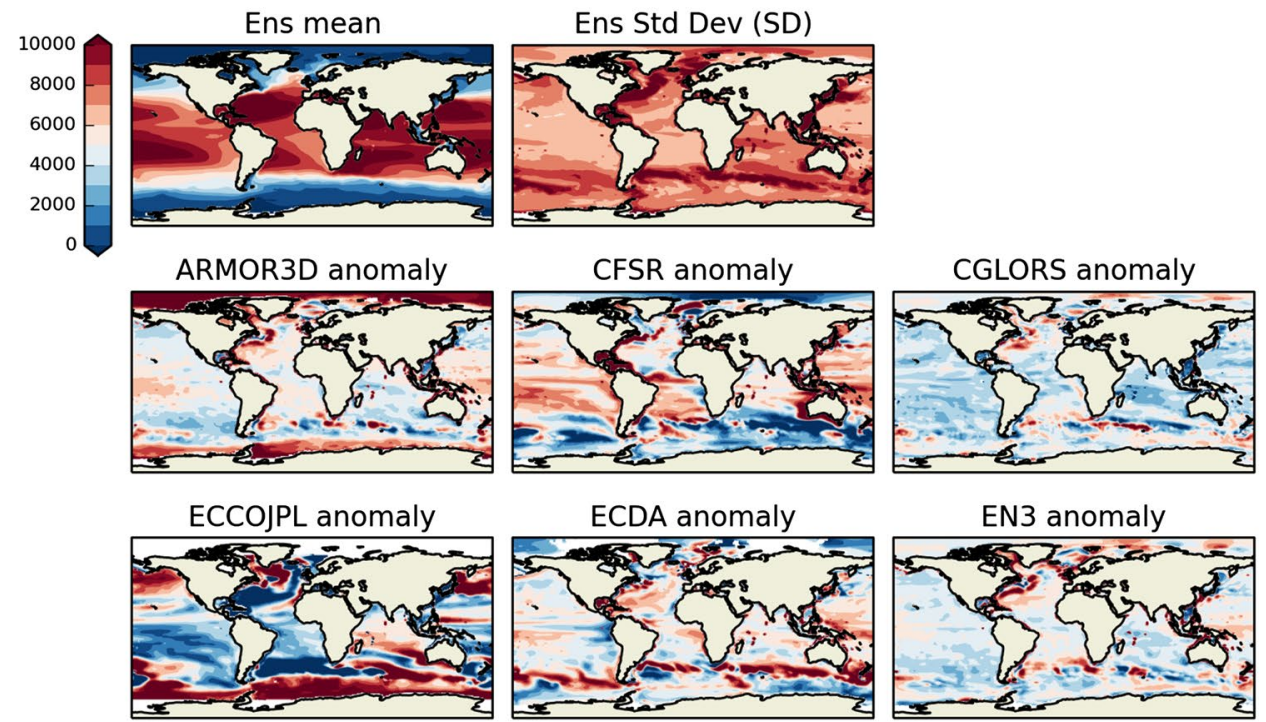

EN3 anomaly

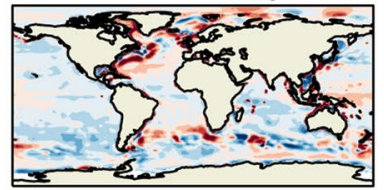

GECCO anomaly

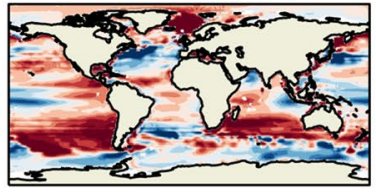

GLORYS2V1 anomaly

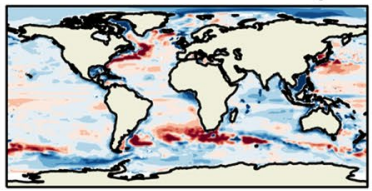

GODAS anomaly

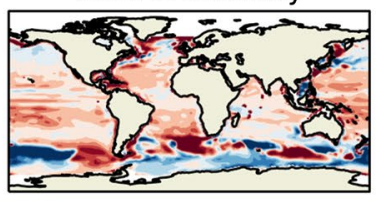

GloSea anomaly

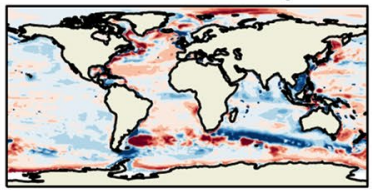

MOVEC anomaly

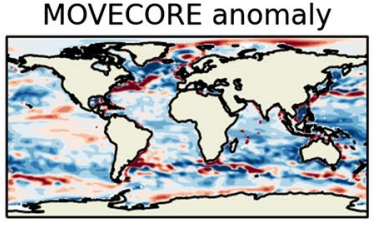

ORAS4 anomaly
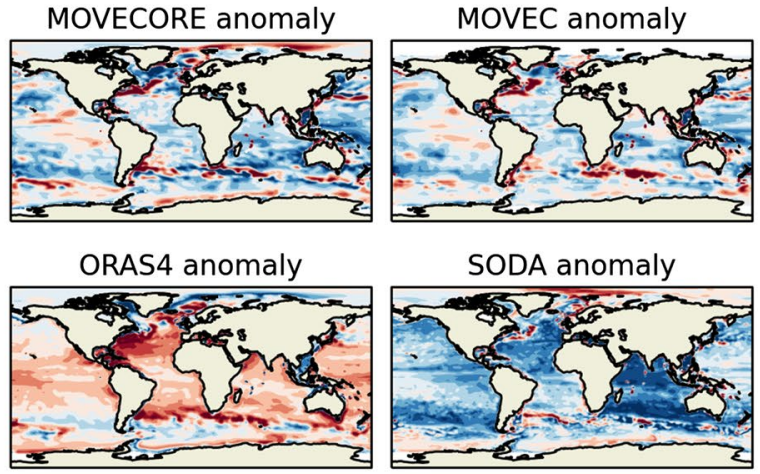

SODA anomaly

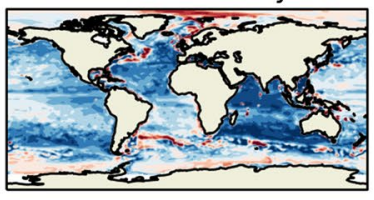

UoR anomaly

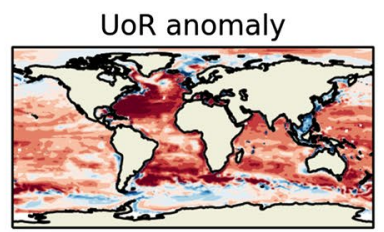

K7 anomaly

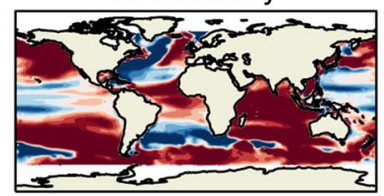

MOVEG2 anomaly

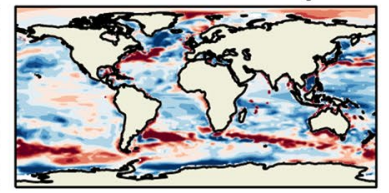

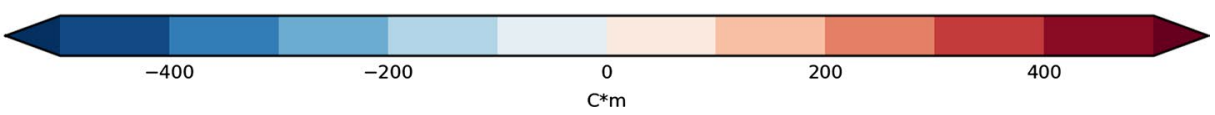


box by simply subtracting the minimum monthly value from the maximum monthly value. The remainder of the analysis presented here is carried out using annual mean values of $\langle\theta\rangle$.

Maps of interannual variability are computed for the period 1993-2009 (except MOVECORE, which uses 1993-2007). The variability for each ORA is computed as the standard deviation of annual values for each grid box after removing a linear trend. Lastly, spatial maps of $\langle\theta\rangle$ change are computed by fitting a linear trend to each grid box over the periods 1970-2009 and 1997-2009, with the latter period intended to characterize ocean heat content changes during the surface warming 'hiatus' period.

In our analysis of interannual variability (calculated for each product following the removal of ORA-specific climatologies), we follow the 'signal-to-noise' definition of Xue et al. (2012). Here, the 'signal' (S) is defined as the temporal standard deviation of the ensemble mean over a specified period. The 'noise' $(\mathrm{N})$ is defined as the temporal average of the standard deviation of ensemble spread over the same period. This definition of $\mathrm{S} / \mathrm{N}$ is thus a measure of the average spread across the ensemble relative to the signal of the ensemble mean. Areas where $\mathrm{S} / \mathrm{N}<1$ can be interpreted as regions where differences in the underlying ocean models tend to dominate over the ability of the available observations and data assimilation schemes to constrain the ORA solutions. In the other spatial map comparisons presented here we often show the ensemble mean (M), the ensemble standard devidation (SD) and the ratio of the two (M/SD) to provide an indication of the spread and level of agreement among ORAs.

\section{Time-mean and amplitude of the seasonal cycle}

The first aspect of our intercomparison is the time-mean $\langle\theta\rangle$ over the 0-700 $\mathrm{m}$ layer for the period 1993-2009 (Figs. 1, 2). The largest differences across the ensemble are mostly associated with areas of high eddy kinetic energy (EKE), such as the Southern Ocean and boundary current regions. The representation of high EKE regions depends strongly on the resolution of the underlying OGCM and also the extent to which the ORA solution is constrained by satellite altimeter data, which can impact subsurface temperature and OHC (Lea et al. 2014). Not all ORAs assimilate satellite altimeter data (Table 1) and those that do may differ according to any errors in the mean dynamic topography (MDT) used in the assimilation (Haines et al. 2011). Differences in MDT and both hydrography and altimeter assimilation methods are particularly important in the Southern Ocean, and may explain the large spread and positive/negative dipoles exhibited in that region. Differences in the North Atlantic sector are likely associated with differing representation of the Atlantic meridional overturning circulation and the associated heat transport (Pohlmann et al. 2013; Valdivieso et al. 2015). While model resolution affects the simulation of the AMOC, studies have shown that the mean value can be reasonably well represented in 1/4 degree models (Roberts et al. 2013), although the associated heat transports are too weak (Haines et al. 2013).

Many of the analyses show a widespread cool or warm bias, relative to the ensemble mean (e.g. SODA, GloSea). Disentangling the roles of differing ocean vertical mixing,
Fig. 2 Zonally averaged anomaly of 0-700 m depthintegrated temperature, relative to the ensemble mean, for individual ORAs. All curves are shown in each panel and plotted in grey or according to the legend. A common data mask has been applied to all products. All values are computed for the period 1993-2009, except for MOVECORE (1993-2007)
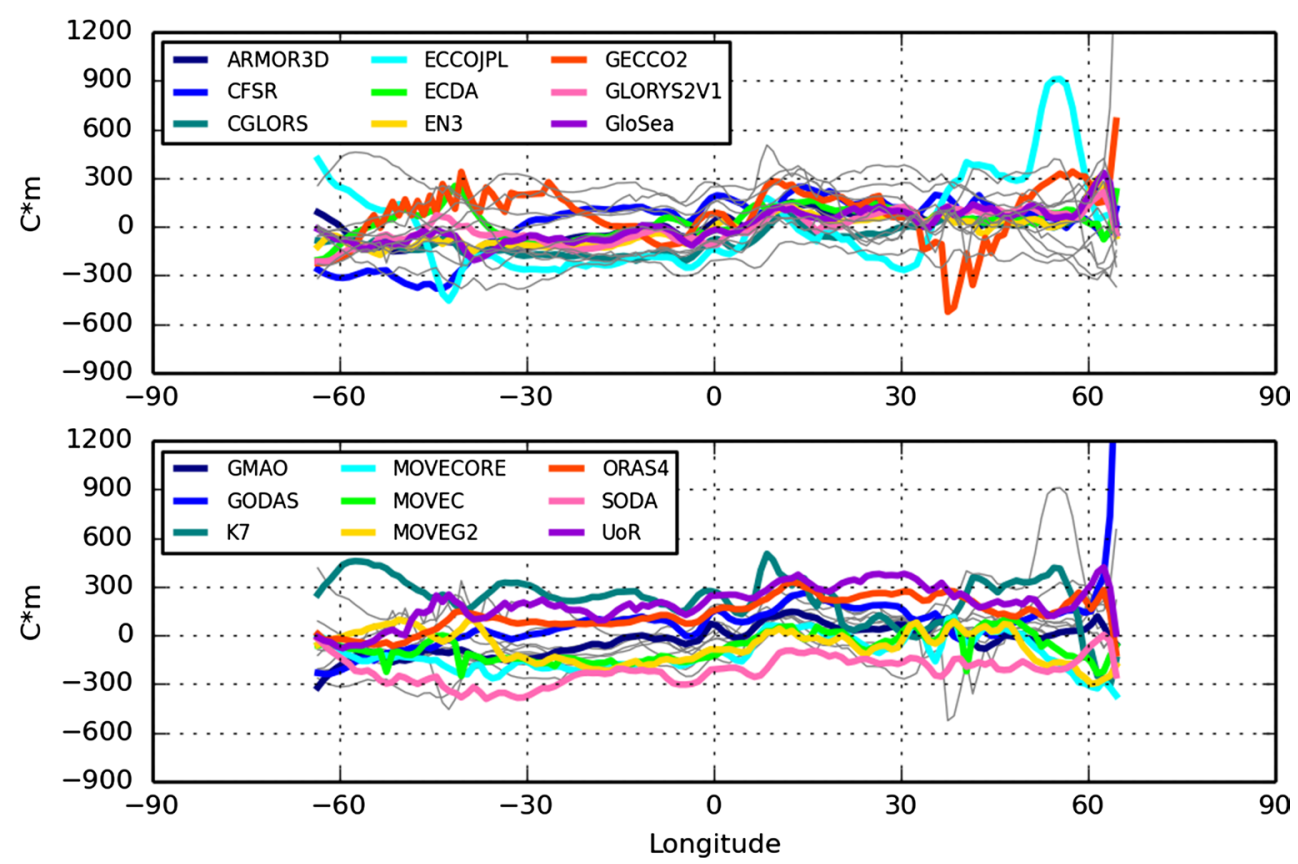
ocean circulation and surface forcings in determining these biases is a challenging problem and requires further and detailed analysis. Errors in both momentum and heat fluxes have a role here (Lee et al. 2013; Valdivieso et al. 2015) and consideration of mixed layer depths may also offer additional insights (Toyoda et al. 2015). The representation of vertical mixing in ocean models remains an area that requires particular attention due to the different mixing schemes, related parameters and the often poorly quantified effects of numerical mixing (e.g. Buchard et al. 2008). Regionally, the departures from the ensemble mean can exceed $\pm 500 \mathrm{Cm}$, or $0.7 \mathrm{C}$ in terms of the depth-averaged temperature (Fig. 1). However, the zonal averages show that all analyses are generally within $\pm 350 \mathrm{Cm}$ (or $0.5 \mathrm{C}$ )
Fig. 3 Top row ensemble mean (M); ensemble standard deviation (SD); and the ratio of the two (M/SD) for the amplitude of the seasonal cycle over the 0-700 m layer. Lower panels the difference between each ORA and the ensemble mean. All values are computed for the period 1993-2009, except for MOVECORE (1993-2007)
Amplitude of $0-700 \mathrm{~m} \mathrm{OHC} \mathrm{seasonal} \mathrm{cycle} \mathrm{in} \mathrm{ocean} \mathrm{analyses}$
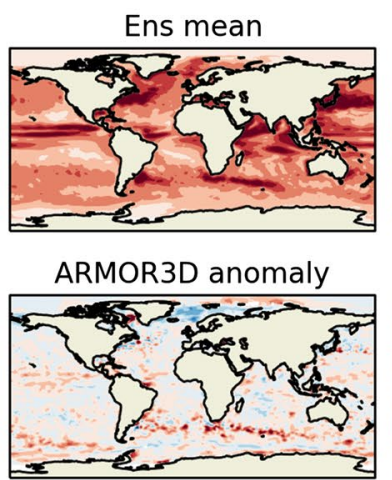

ECCOJPL anomaly

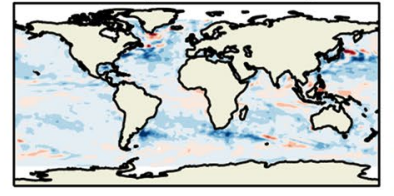

GECCO anomaly

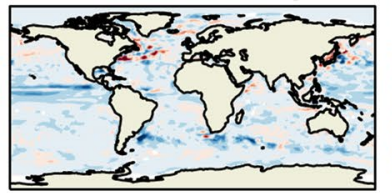

GODAS anomaly
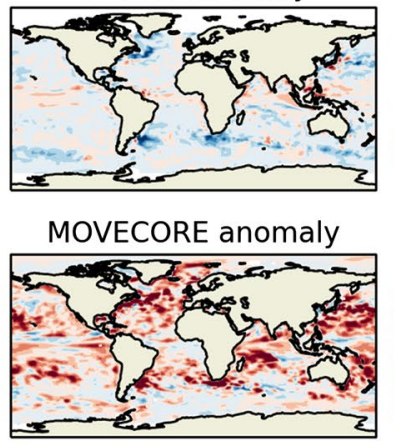

ORAS4 anomaly

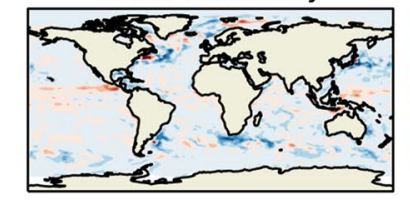

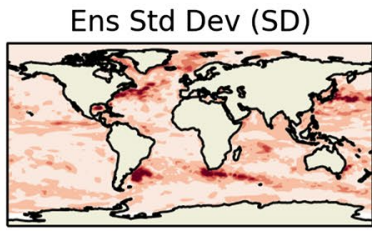

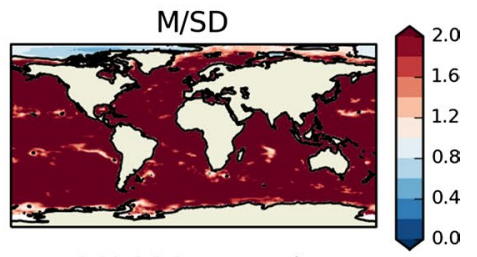

CGLORS anomaly

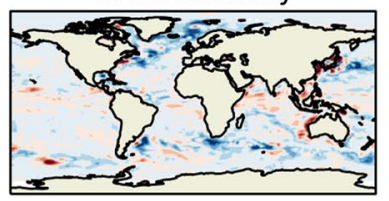

ECDA anomaly

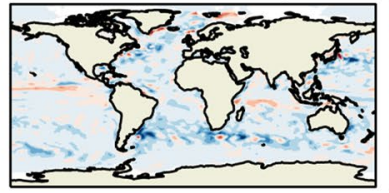

GLORYS2V1 anomaly

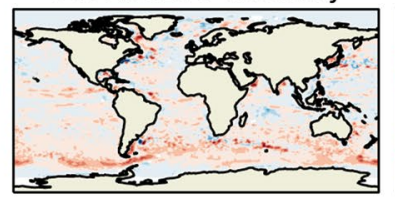

GloSea anomaly

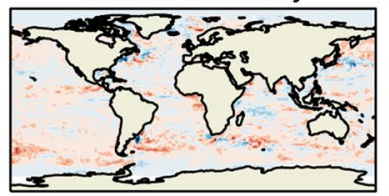

MOVEC anomaly

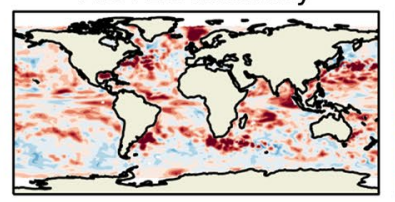

SODA anomaly

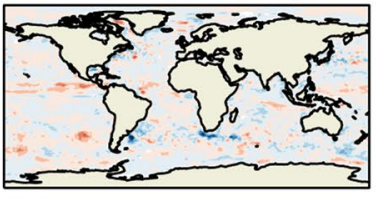

EN3 anomaly

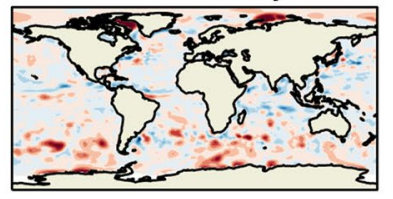

GMAO anomaly

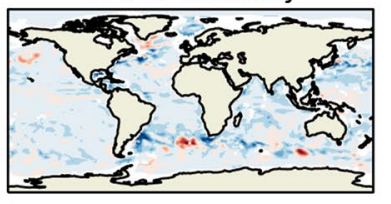

K7 anomaly

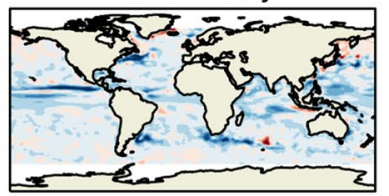

MOVEG2 anomaly

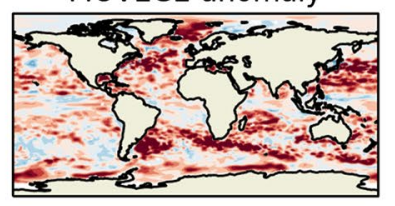

UoR anomaly
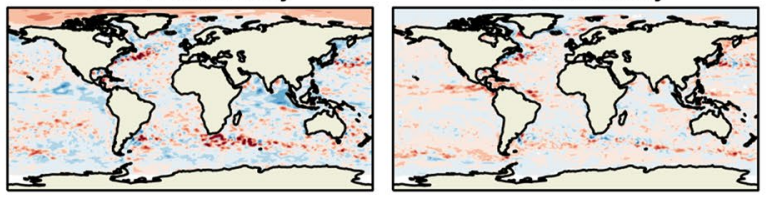

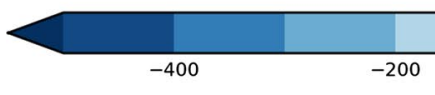

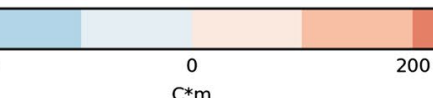

C*m

400 
Fig. 4 Zonally averaged amplitude of the seasonal cycle in the 0-700 m layer for individual ORAs. All curves are shown in each panel and plotted in grey or according to the legend. A common data mask has been applied to all products. All values are computed for the period 1993-2009, except for MOVECORE (1993-2007)
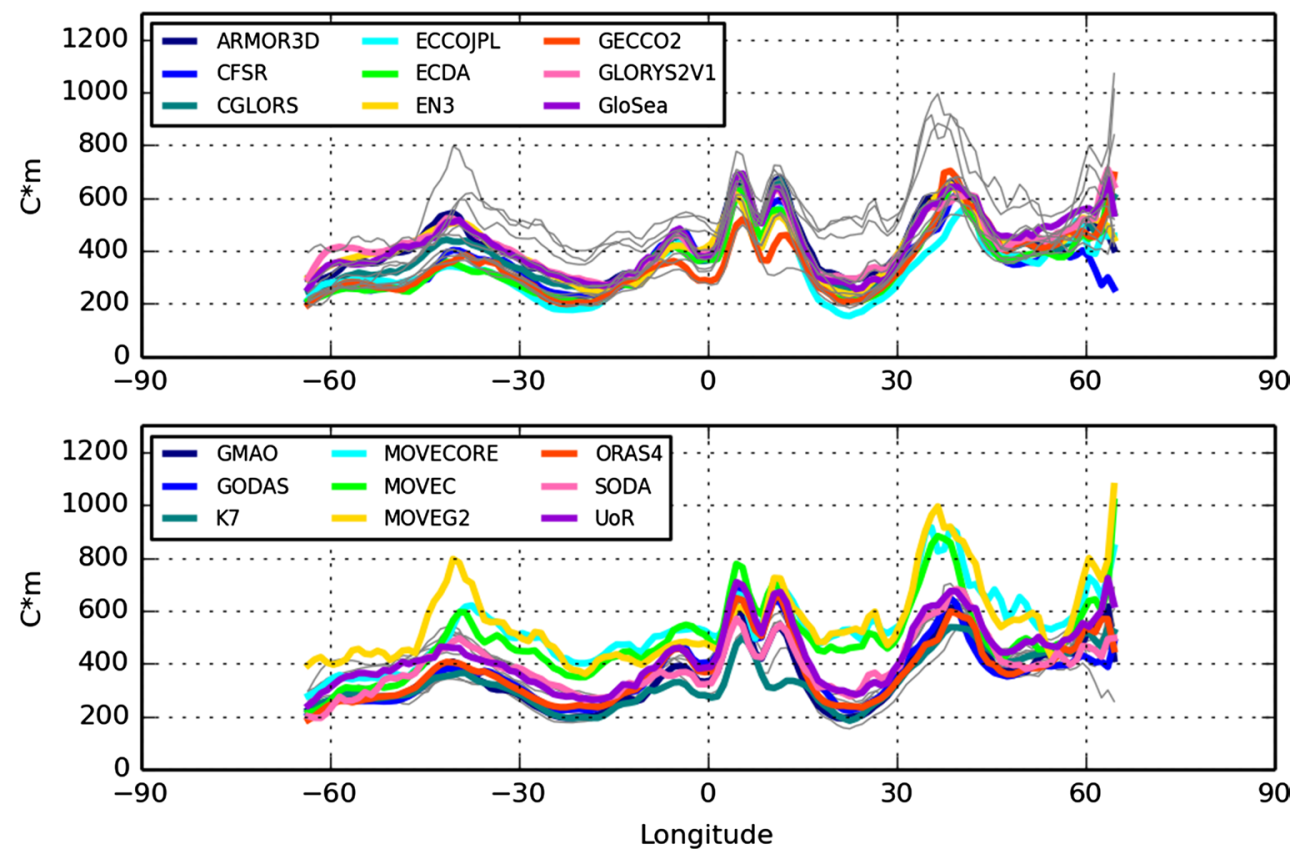

of the ensemble mean between $60 \mathrm{~S}$ and $60 \mathrm{~N}$ (Fig. 2). The increased spread north of $60 \mathrm{~N}$ may be indicative of differing representation of the Arctic marginal ice zones and may be exacerbated by the reduction of ocean grid points at these latitudes.

The amplitude of the seasonal cycle of $\langle\theta\rangle$ over the 0-700 $\mathrm{m}$ layer is well constrained by the ORA ensemble over the vast majority of the ocean (Fig. 3). The largest differences among the ORAs are often associated with areas of high EKE, as well as the North-west Pacific and central Indian Ocean. There is no obvious relationship between the individual ORAs representation of the ocean meanstate and the amplitude of the seasonal cycle, as seen by comparing Figs. 1 and 3. The zonal average plots show a similar morphology among the ORAs for the seasonal cycle amplitude (Fig. 4), with a characteristic off-equatorial double-peak and maxima around 40N/S-corresponding to the latitude of maximum wind stress curl and seasonal changes in Ekman divergence. Differences in the locations of the peaks at about $40 \mathrm{~N} / \mathrm{S}$ are therefore likely indicative of different wind-driven circulations among the ORAs. In addition, the MOVE products show another peak around $65-70 \mathrm{~N}$, in the region of the northern hemisphere marginal ice zone. Generally, the MOVE products show a larger amplitude seasonal cycle than the other ORAs and particularly pronounced peaks at $40 \mathrm{~N} / \mathrm{S}$. Differences across the ensemble can arise from the representation of ocean vertical mixing, surface fluxes and also the data assimilation.

\section{Interannual variability}

ORA estimates of interannual variability over the $0-300 \mathrm{~m}$ layer (Fig. 5) show a $\mathrm{S} / \mathrm{N}$ ratio $>1$ over most of the North Atlantic, Pacific and Indian Oceans. The South Atlantic and Southern Ocean typically show $\mathrm{S} / \mathrm{N}$ values $<1$, due to weak signal and a combination of weak signal and relatively large ensemble noise, respectively. Again, areas of high EKE emerge as the regions of largest ensemble spread. Interannual variability in the products without an OGCM (i.e. ARMOR3D and EN3) is generally lower than the other ORAs, particularly in the Southern Ocean where observations are sparse and mesoscale variability is high.

For the 300-700 m layer, we see a dramatic reduction in $\mathrm{S} / \mathrm{N}$ ratio for the ensemble (Fig. 6). Areas where $\mathrm{S} / \mathrm{N}>1$ are still found throughout large regions of the Pacific, but limited to isolated areas in the tropical Indian Ocean and the Northeast Atlantic. Compared to the 0-300 m layer, the change in $\mathrm{S} / \mathrm{N}$ appears to be dominated by a reduction in the signal, with the noise having a similar spatial pattern and magnitude.

The comparison of interannual variability for the $700-6000 \mathrm{~m}$ layer (Fig. 7) shows that there is very little agreement in the deep ocean such that $\mathrm{S} / \mathrm{N}<1$ in almost all locations. We note that the products without an OGCM (ARMOR3D and EN3) generally have lower variability than the other ORAs. This is not surprising, as for the majority of this depth range, these products 
Fig. 5 Interannual variability of depth-integrated temperature for the $0-300 \mathrm{~m}$ layer (Celsius meters) for each ORA, computed as the temporal standard deviation of annual mean values for each grid box after removing a linear trend. White areas indicate where no data are available. Also shown is the ensemble average temporal standard deviation ('signal', S), the temporal average of the ensemble standard deviation ('noise', $\mathrm{N}$ ), and the ratio of the two $(\mathrm{S} / \mathrm{N})$. The ensemble values (top row) are computed for each grid box based on all available data. All values computed for 1993-2009 except for MOVECORE (1993-2007)
Interannual variability in 0-300m OHC (1993-2009)
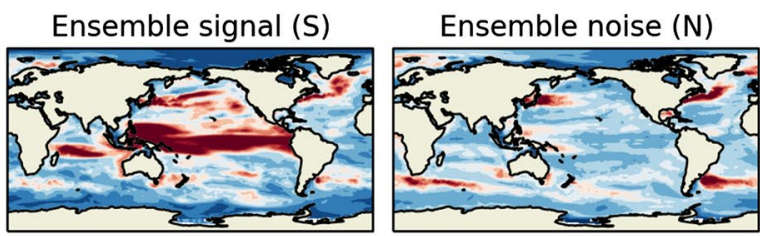

ARMOR3D

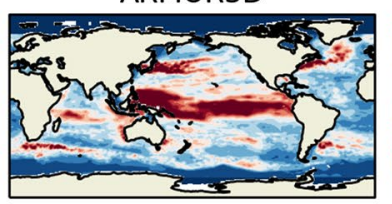

CFSR
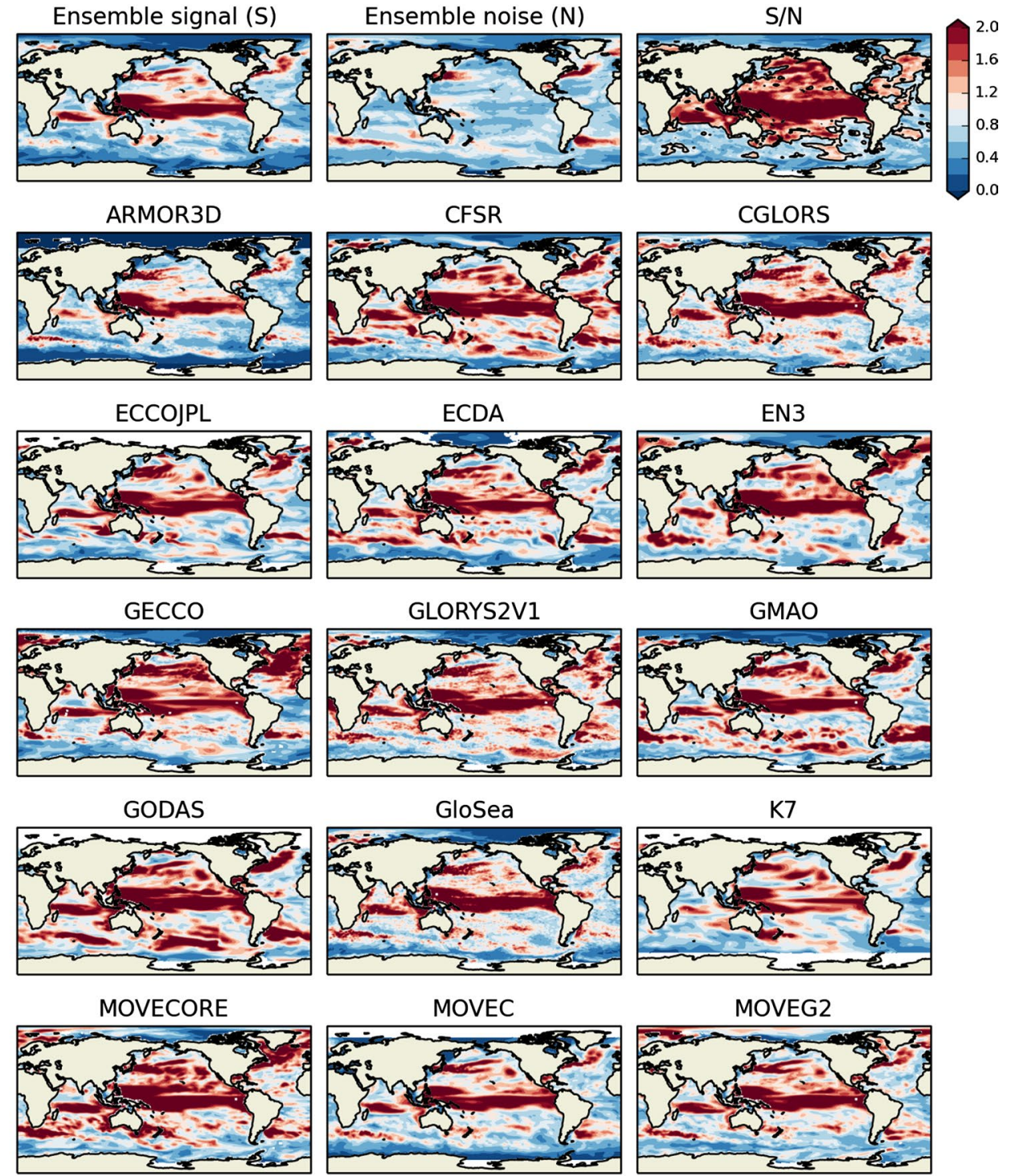

ORAS4

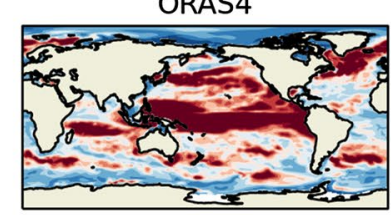

SODA
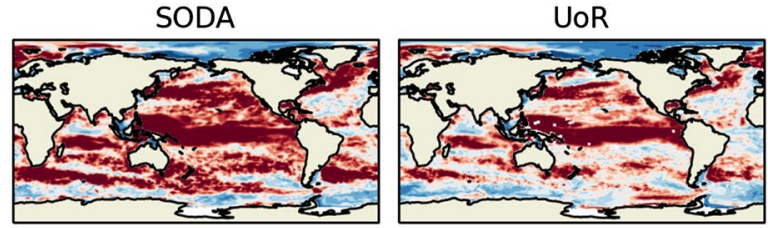

$<$
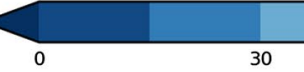

$\mathrm{C}^{*} \mathrm{~m}$ are unconstrained by observations and relax to climatology. In contrast, the ORAs that include an OGCM component are free to generate variability that is consistent with the model dynamics, even if it is not constrained by in situ observations. Some models show particularly large variability in the Southern Ocean and North Atlantic (e.g. GECCO, GODAS), but it is not clear whether this can be considered true interannual variability, or whether it is related to drift associated with long-timescale adjustments in the deep ocean. We also note that there appears to be a relationship between the regions of high signal and high noise for this depth range. The patterns show a strong resemblance to the distribution of mode waters (Hanawa and Talley 2001) and also include regions associated with 
Fig. 6 Same as Fig. 5, but for the 300-700 $\mathrm{m}$ layer

Interannual variability in 300-700m OHC (1993-2009)
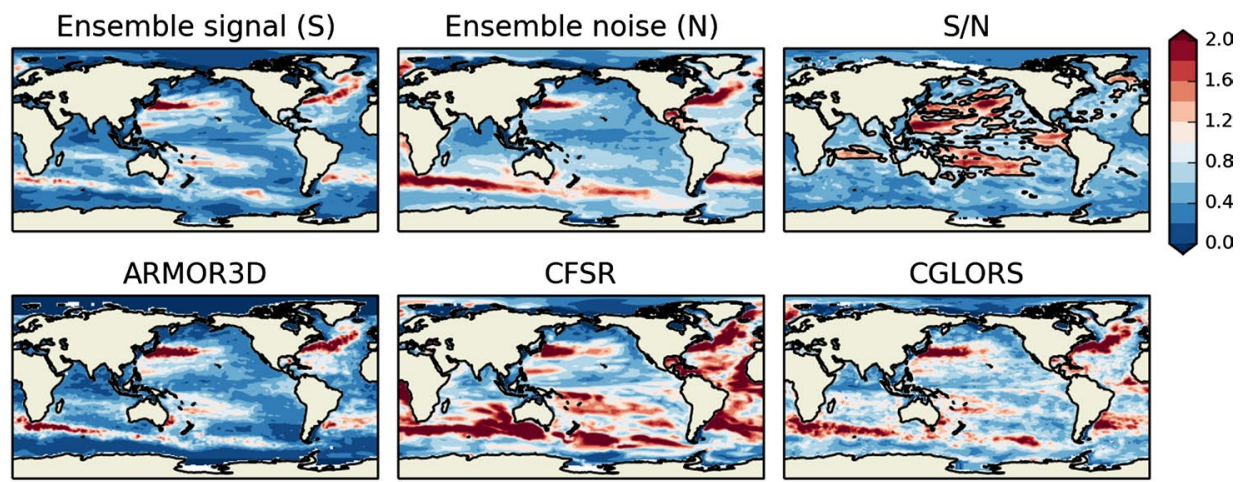

CFSR

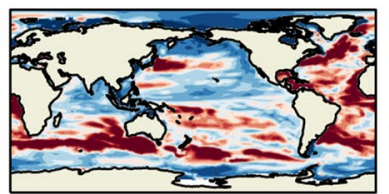

CGLORS

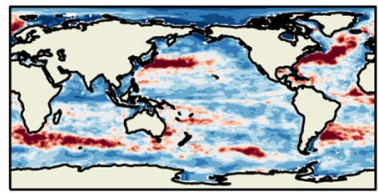

EN3
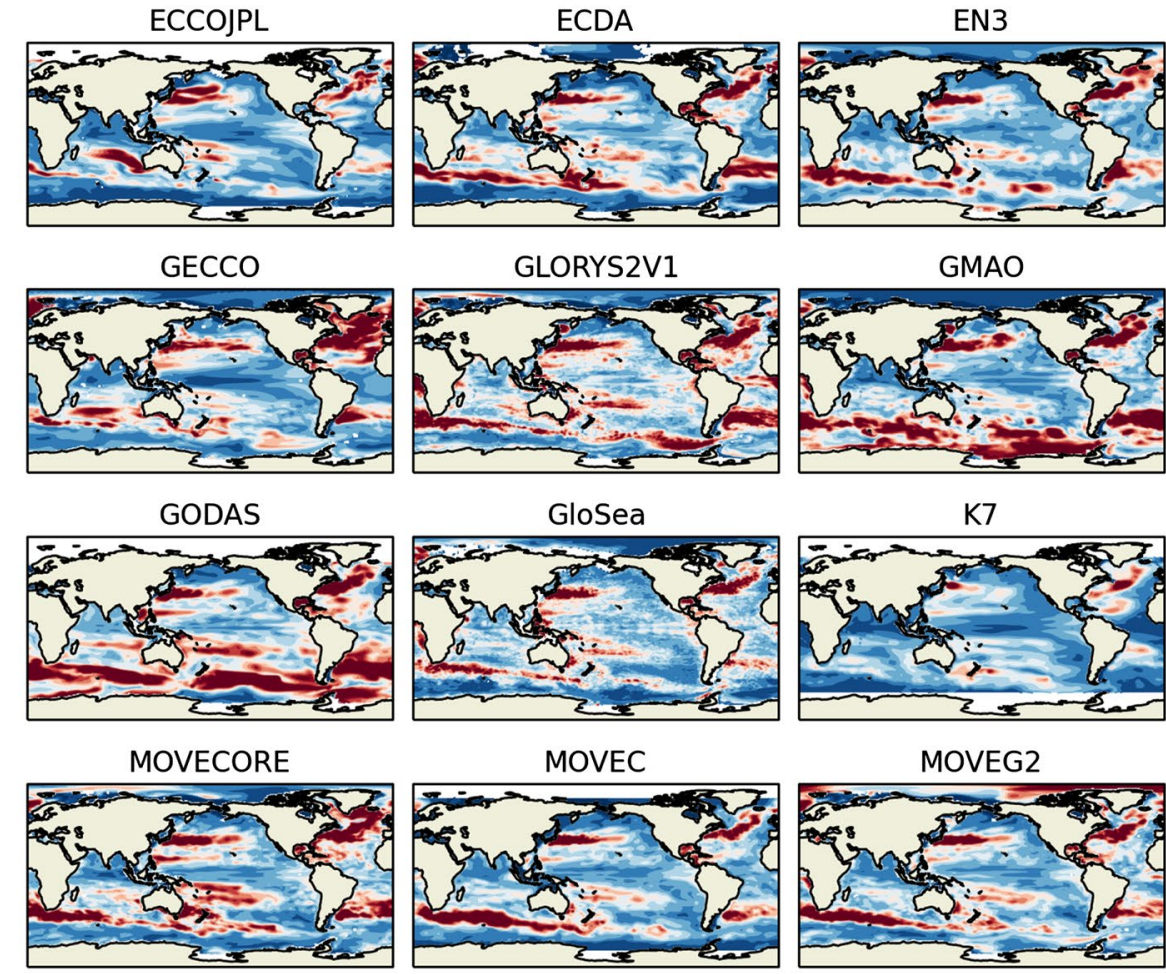

ORAS4

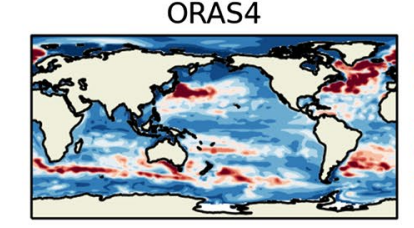

SODA
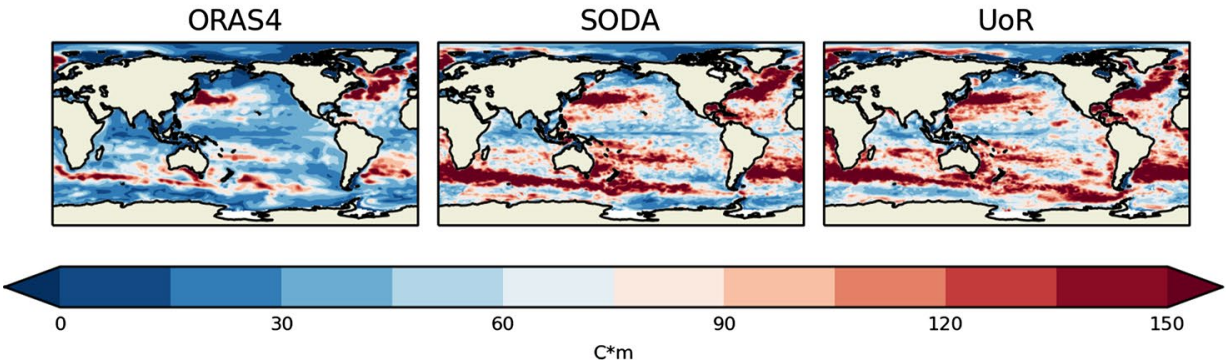

open ocean convection and deep water formation (Marshall and Schott 1999). The implication is that the different ORAs vary in their representation of these water formation processes, owing to different surface forcings and representation of vertical mixing, as discussed in the previous section.

\section{Time series of OHC change}

Similar to previous studies (Lyman et al. 2010; Palmer et al. 2010; Abraham et al. 2013), ORA time series of OHC change for the 0-700 $\mathrm{m}$ vary in a number of aspects, including: interannual variations; the estimated response to the 
Fig. 7 Same as Fig. 5, but for the 700-6000 m layer

Interannual variability in 700-6000m OHC (1993-2009)
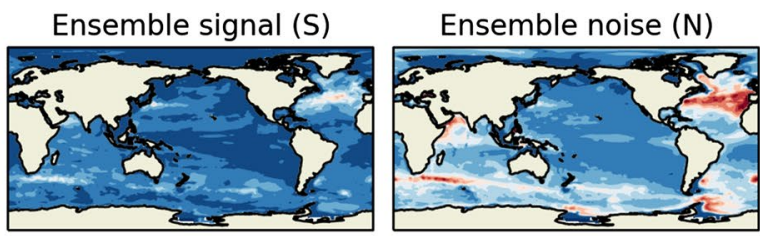

CFSR
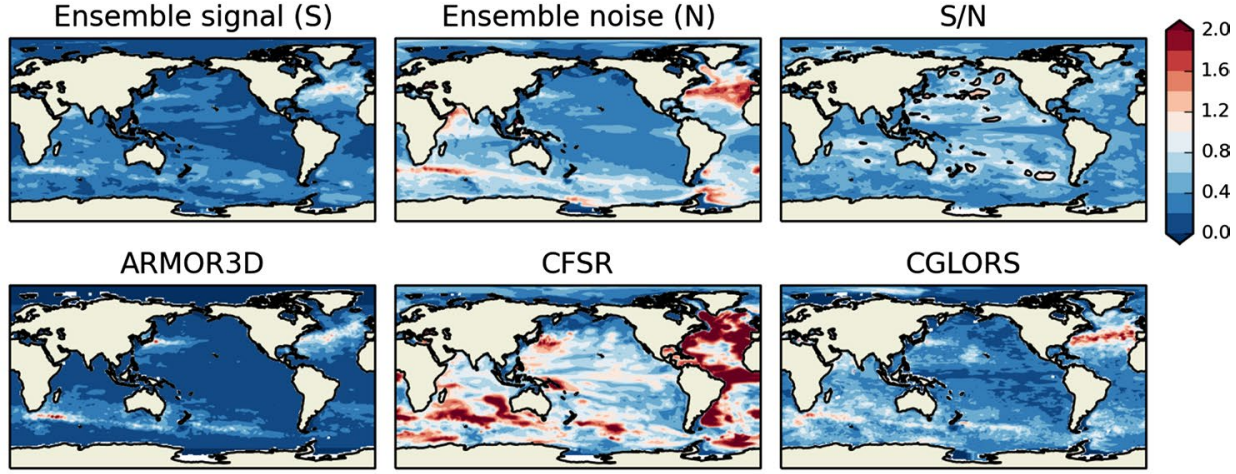

CGLORS

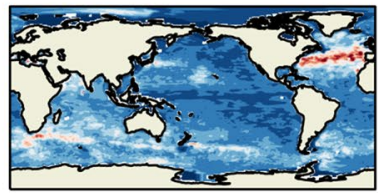

EN3
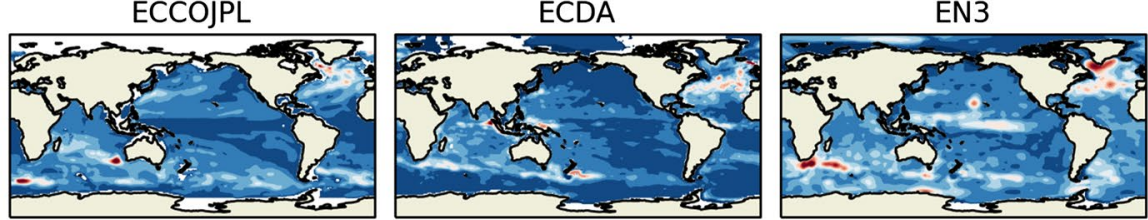

GLORYS2V1
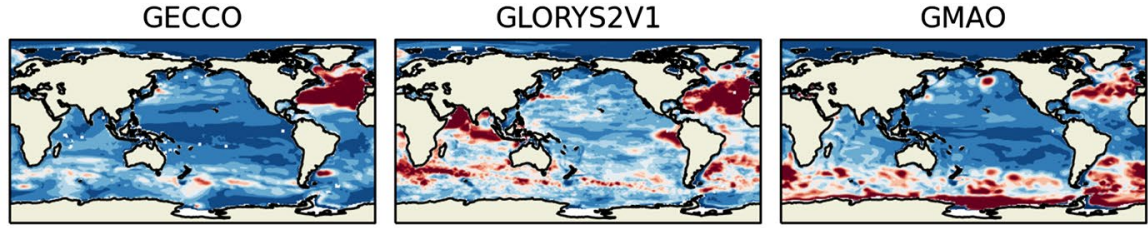

GloSea
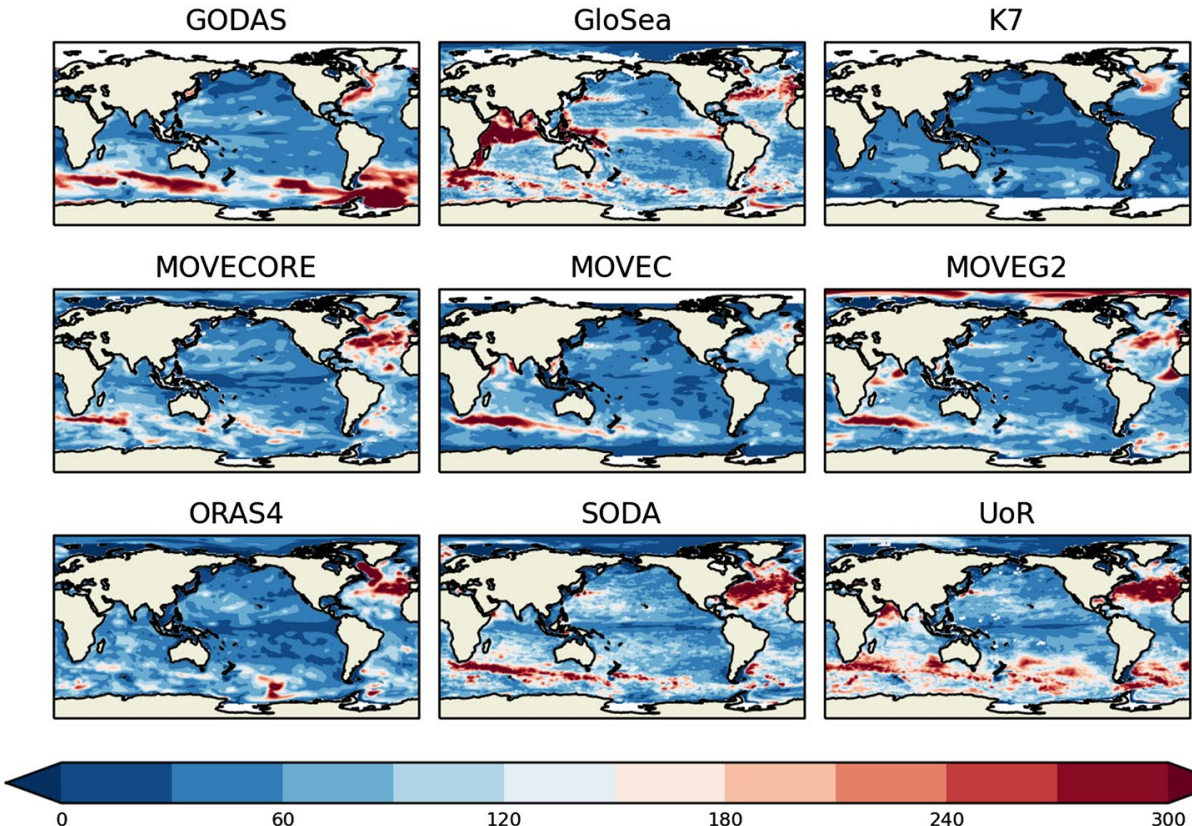

120

$C^{*} m$

major volcanic eruptions in 1963, 1982 and 1991; decadal and multi-decadal trends (Fig. 8). The range of trends and spread among the analyses for the global ocean is similar to the statistical products presented in the IPCC $5^{\text {th }}$ Assessment report (Rhein et al. 2013). A number of products appear to show large initialization or spin-up 'shock'-i.e. an initial and rapid change in $\mathrm{OHC}$ in the first few years of the time series. Separating the time series by hemisphere illustrates the larger spread in the Southern Hemisphereconsistent with the lack of observations over this domain.

Many ORAs qualitatively support the findings of Balmaseda et al. (2013b); exhibiting enhanced ocean heat uptake below $300 \mathrm{~m}$ from the mid-1990s or early 2000s (Fig. 9a, b). This includes both of the statistical analyses 

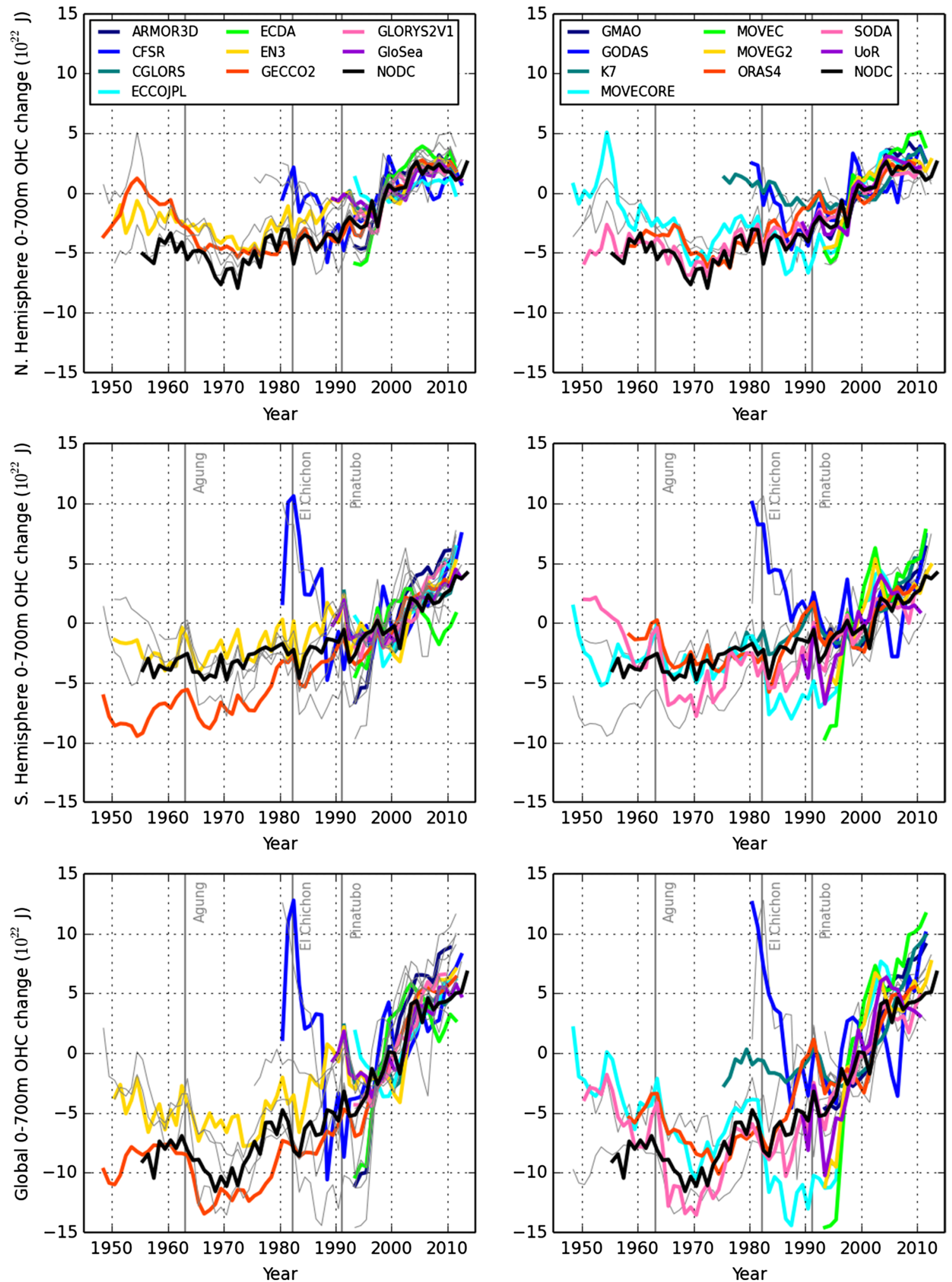

Fig. 8 Time series of ocean heat content change, relative to a 1993-2007 baseline. All curves are shown in each panel and plotted in grey or according to the legend. To aid comparison the NODC product has been highlighted in black in all panels

(ARMOR3D and EN3), showing that an OGCM is not required to capture this behavior. Balmaseda et al. (2013b) suggested that the additional heat uptake below $300 \mathrm{~m}$ simulated by ORAS4 was associated with changes in the Pacific Decadal Oscillation and also a weakening of the AMOC. However, it remains unclear how much of this 

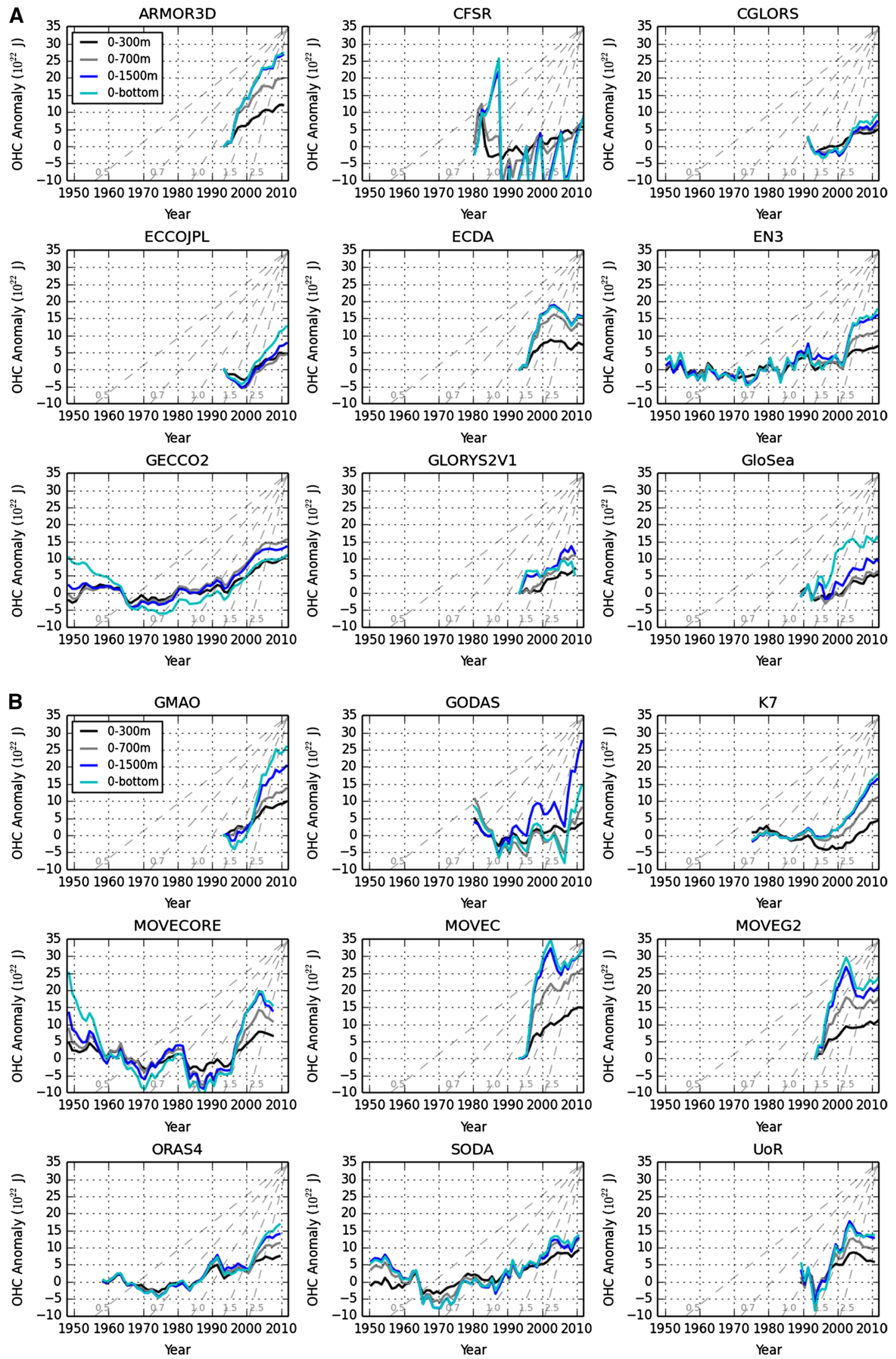

Fig. 9 Time series of ocean heat content change for a range of depth intervals, computed to a baseline period of 1948-1993 for illustrative purposes. The dashed grey lines indicate the equivalent heating rate $\left(\mathrm{W} \mathrm{m}^{-2}\right)$ computed for Earth's surface area 
enhanced deep ocean heat uptake might be explained as a sampling artifact. Cheng and Zhu (2014) showed that the dramatic improvement in ocean sampling during the initiation of Argo resulted in an artificial jump in OHC over 0-700 m during 2001-2003. Given the lack of historical in situ ocean observations south of about 20S, it seems plausible that much of the increase in deep ocean heat uptake demonstrated by the ORAs during the 2000s may result from Argo suddenly 'revealing' a longer-term Southern Ocean warming signal (Roemmich et al. 2015).

Some of the full depth OHC time series show very large rates of change-exceeding $3 \mathrm{~W} \mathrm{~m}^{-2}$ globally during some periods-and such changes cannot be reconciled with satellite-based reconstructions of Earth's energy imbalance (Allan et al. 2014) or the global sea level budget (Church et al. 2011). CFSR (Fig. 9a) shows very some large, almost oscillatory, changes in OHC below $700 \mathrm{~m}$ that may be linked to previously documented discontinuities in deep ocean temperature and salinity (Xue et al. 2011). For the MOVE products (Fig. 9b), the large rates of $\mathrm{OHC}$ change are a known feature related to the use of vertical empirical orthogonal functions in those products.

Since the rate of $\mathrm{OHC}$ change is the quantity of primary interest in the context of the understanding Earth's energy imbalance, we fit rolling 5-year linear trends to each the ORA time series, following Smith et al. (2015). These time series are used to generate an ORA ensemble mean and standard deviation, for the various depth levels, integrated over the globe and each hemisphere with rates of OHC change expressed in $\mathrm{W} \mathrm{m}^{-2}$ relative to the surface area of the Earth (Fig. 10). We omit CFSR and GODAS due to their large initialization 'shock' (Fig. 8) and also MOVECORE because the simulation terminates in 2007, resulting in a 15-member ORA ensemble for the period 1993-2009.

As one would expect, the 0-300 m layer shows a relatively narrow spread, particularly for the Northern Hemisphere (Fig. 10). It is interesting to note that the Northern and Southern Hemisphere appear to be anti-correlated in these upper layers and this could be related to changes in the AMOC and associated changes in inter-hemispheric heat transport. The magnitude of mean global OHC change for the $0-300 \mathrm{~m}$ layer peaks at about $0.5 \mathrm{~W} \mathrm{~m}^{-2}$. The 300-700 m layer shows similar rates and sign of OHC change in both hemispheres, but a much larger spread in the Southern Hemisphere. Peak rates of the mean global $\mathrm{OHC}$ change are about $0.4 \mathrm{~W} \mathrm{~m}^{-2}$ for this layer. Below $700 \mathrm{~m}$ the mean global rate of $\mathrm{OHC}$ change is dominated by the Southern Hemisphere with the peak rate around 1997/1998. OHC integrated over the full column (Fig. 10, 0-6000 m) shows a fairly steady mean global rate of $0.9 \pm 0.8 \mathrm{~W} \mathrm{~m}^{-2}$ for the period 1995-2002 that drops to $0.2 \pm 0.6 \mathrm{~W} \mathrm{~m}^{-2}$ for the period 2004-2006 (error bars indicate 1 standard deviation of ensemble mean), in qualitative agreement with the findings of Smith et al. (2015). However, there is no evidence in our ORA ensemble mean of the 'spike' in OHC trends reported by Smith et al. in the early 2000 s.

In terms of the ORA ensemble standard deviation, the spread in systematically less in the Northern Hemisphere than the Southern Hemisphere. This is probably a combination of both the better observational coverage and the lesser ocean volume north of the equator. There is a tendency towards reduced spread for all series over time, but this is not monotonic. Although the data here are limited to 2009, we appear to see the impact of Argo observations becoming available in the sharp reduction in ORA ensemble spread for the Southern Hemisphere below $300 \mathrm{~m}$ after about 2004 (Fig. 10).

\section{Spatial patterns of $\mathrm{OHC}$ change}

For the ORAs with data available back to 1970 (EN3, GECCO, ORAS4, SODA), we calculate linear trends in OHC for three layers $(0-300,300-700$, and $700 \mathrm{~m}$ to bottom). For the upper $300 \mathrm{~m}$ (Fig. 11), the large scale pattern of warming is well-captured by the available ORAs, even in wide areas of the Southern Ocean, and there is agreement on the enhanced warmth of the North Atlantic sub-polar gyre relative to the global oceans. The equatorial Pacific and Indian oceans are areas where the ORA ensemble standard deviation exceeds the mean trend. This lack of agreement could be related to the large interannual variability in these regions associated with ENSO which will promote larger spread in the long-term trends through 'end point' effects. For 300-700 m (Fig. 12), the agreement across ORAs is substantially reduced, although there are some still some areas (e.g. North Atlantic) where the signals appear to be common across models. It is also surprising that some signals in the Southern Ocean appear to be consistent across products. However, the number of ORAs available for this comparison is limited $(\mathrm{N}=4)$ so we should treat such evidence of 'agreement' across products with caution. For the $700 \mathrm{~m}$-bottom layer (Fig. 13), the ensemble mean and spread across the ensemble is dominated by the very large signals in the GECCO product: this ORA exhibits a strong warming in the Atlantic and Sourthern Ocean and a cooling in the Indo-Pacific. Given the absence of strong observational constraints for this depth range during this period, it seems likely that these signals are unrepresentative of the real ocean and probably related to adjustment of the OGCM.

To evaluate the level of agreement in the spatial patterns of heat uptake and heat rearrangement by the ocean during the recent slow-down in global warming, we 

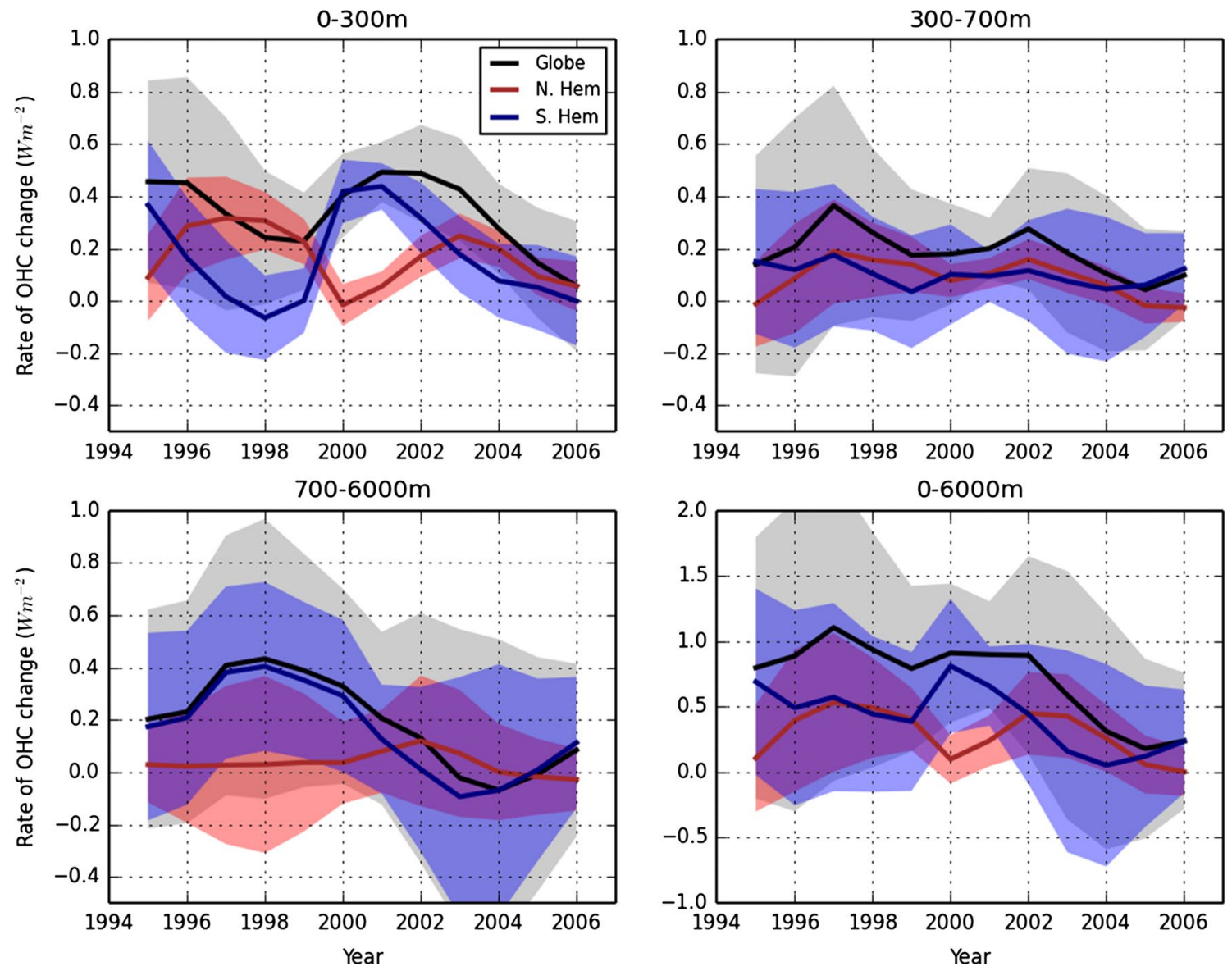

Fig. 10 5-year rolling trends of ocean heat content change over various depth layers for: the Globe (black); Northern Hemisphere (red); and Southern Hemisphere (blue). The solid lines show the ensemble mean with shaded regions indicating \pm 1 standard deviation. Changes

are expressed as equivalent heating rate, in $\mathrm{W} \mathrm{m}^{-2}$, relative to Earth's surface area. Trends plotted relative to the mid-point of each 5-year period. Results are based on 15 ORAs as described in the text

Fig. 11 Trends in $0-300 \mathrm{~m}$ vertically-integrated temperature (Celsius meters per year) for the period 1970-2009. White areas indicate where no data are available. Also shown is the ensemble mean trend $(M)$, the standard deviation of ensemble trends (SD), and the ratio of the two (M/SD). The ensemble values (top row) are computed for each grid box based on all available data
Trends in 0-300m OHC (1970-2009)

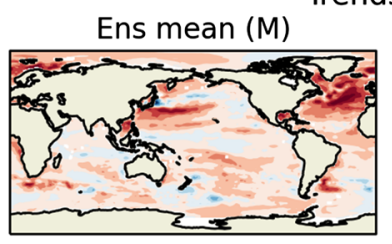

$$
\text { EN3 }
$$

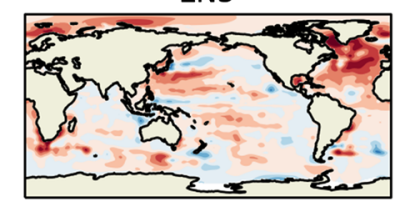

SODA

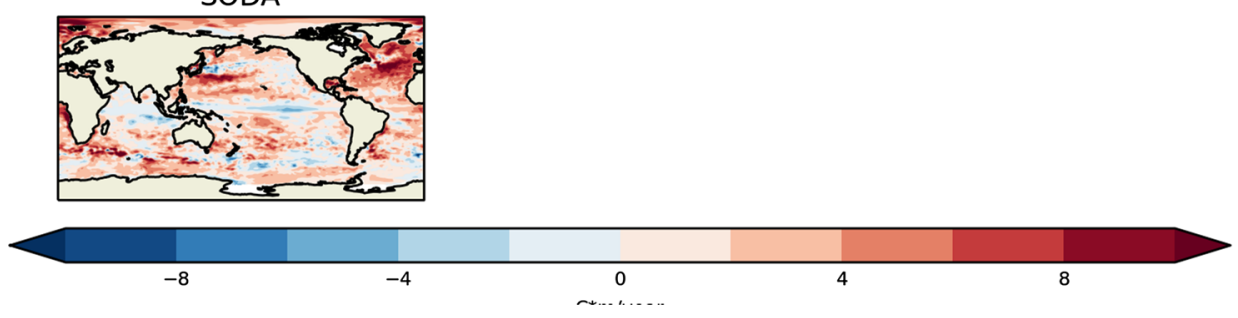

Ens Std Dev (SD)

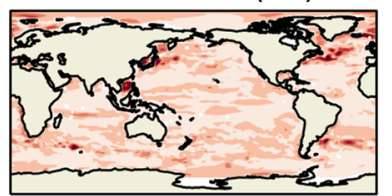

GECCO
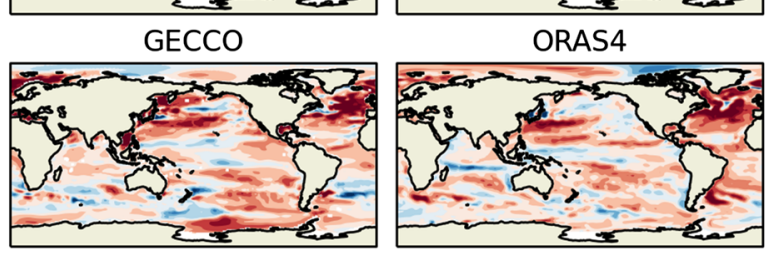

ORAS4

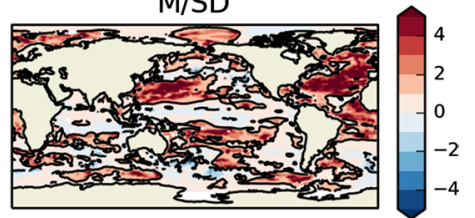

$-4$

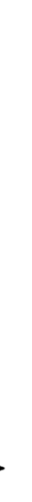


Fig. 12 Same as Fig. 11, but for the 300-700 $\mathrm{m}$ layer

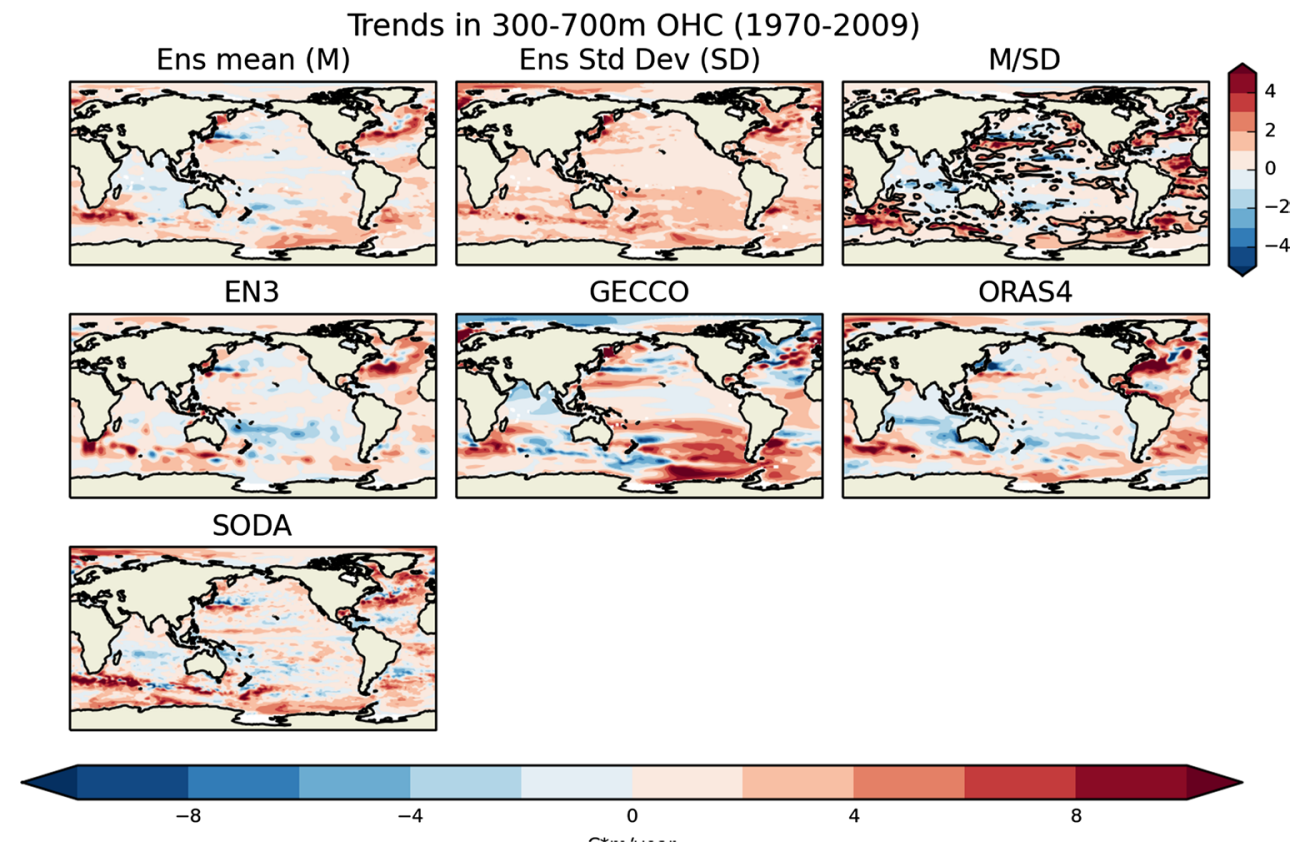

Fig. 13 Same as Fig. 11, but for the 700-6000 m layer

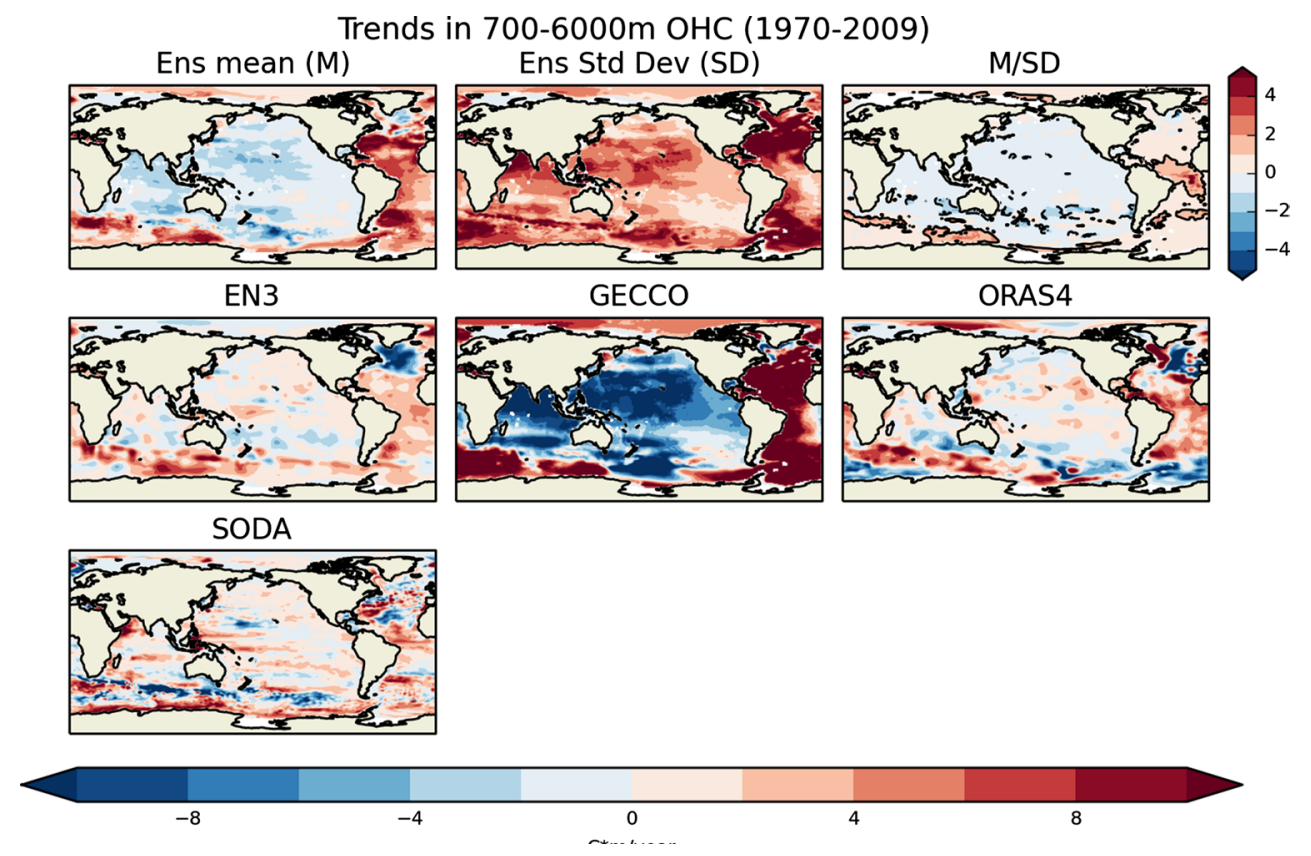

calculate spatial trends in OHC for the period 1997-2009. For the upper $300 \mathrm{~m}$ (Fig. 14), ORAs show agreement in a dipole pattern of warming in the West Pacific and cooling in the East Pacific. This is consistent with previous studies documenting increased sea surface heights and ocean temperatures in the West Pacific warm pool associated with the negative phase of the Pacific Decadal Oscillation (PDO) and a sustained increase in the Pacific trade winds (e.g. England et al. 2014). Although there is some agreement for a pattern of warming in the tropical and north Atlantic, there are large areas where the ORA ensemble spread exceeds the ensemble mean, which is perhaps surprising given that it is one of the best-observed regions of the global oceans. This may be indicative of the influence of dynamic processes, which are likely to vary among ORAs, as discussed in previous sections. Noise across the ensemble is largest in areas of ocean fronts, and there is very little agreement in the sign or magnitude trends in the Southern Ocean, likely reflecting the relative lack of observations in this region. 
Fig. 14 Trends in $0-300 \mathrm{~m}$ vertically-integrated temperature (Celsius meters per year) for the period 1997-2009. White areas indicate where no data are available. Also shown is the ensemble mean trend $(\mathrm{M})$, the standard deviation of ensemble trends $(\mathrm{SD})$, and the ratio of the two (M/SD). The ensemble values (top row) are computed for each grid box based on all available data

Trends in 0-300m OHC (1997-2009)
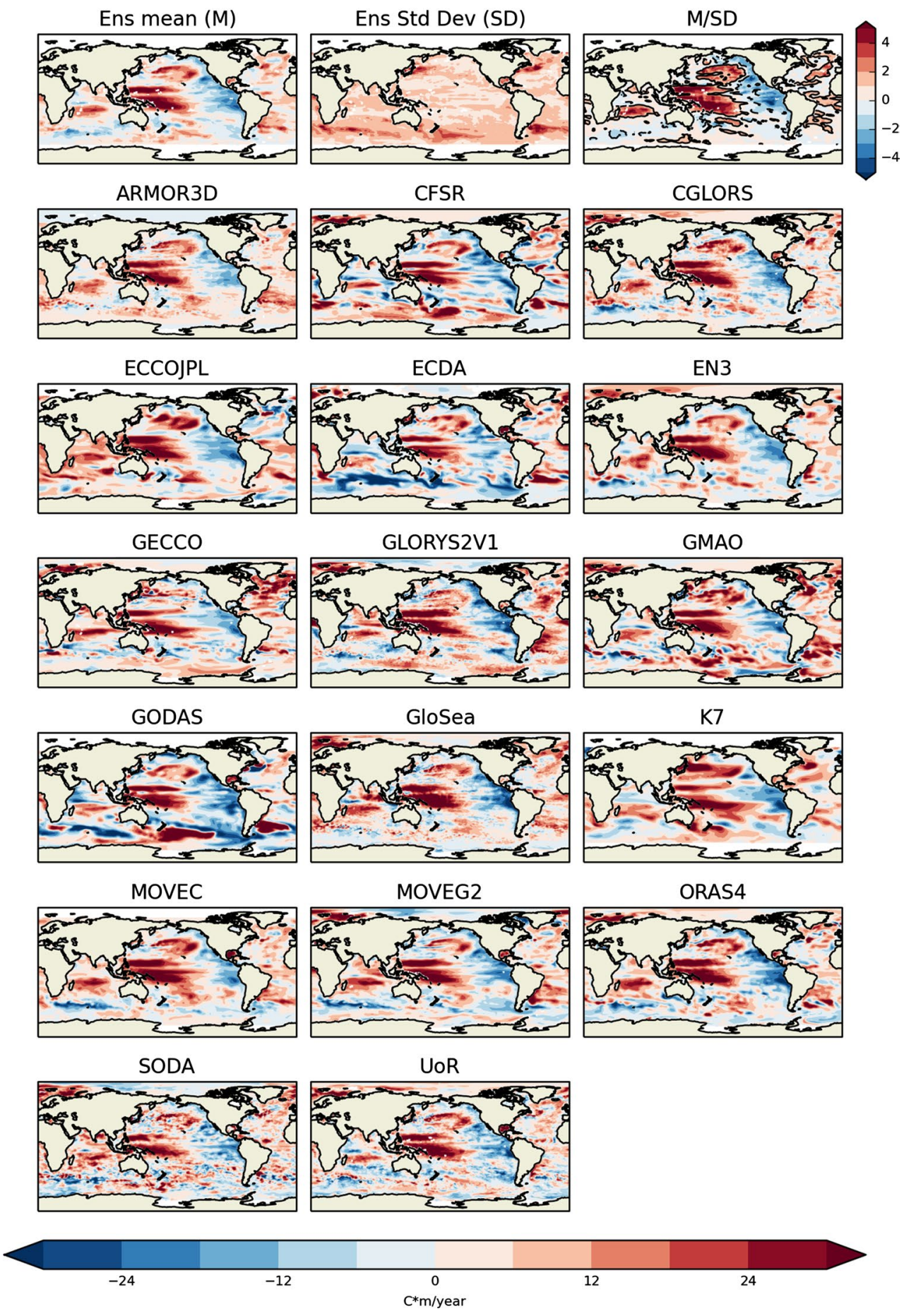

For the deepest layer (700 m to bottom, Fig. 16), there is

For 300-700 m depth range (Fig. 15), agreement across the ensemble is limited to selected regions of sub-tropical convergence in the West Pacific and the North Atlantic sub-polar gyre. Ensemble spread is largest in the Southern Ocean, with products showing no agreement on whether there has been warming or cooling in this layer during this period. virtually no agreement across ORAs for OHC trends during 1997-2009. Although the ensemble mean shows a particularly strong warming in the North Atlantic and more widespread warming in the Southern Ocean, there is no consensus on the magnitude of change. Perhaps notably, both ARMOR3D and EN3 (products that do not include 
Fig. 15 Same as Fig. 14, but for the 300-700 $\mathrm{m}$ layer

Trends in 300-700m OHC (1997-2009)
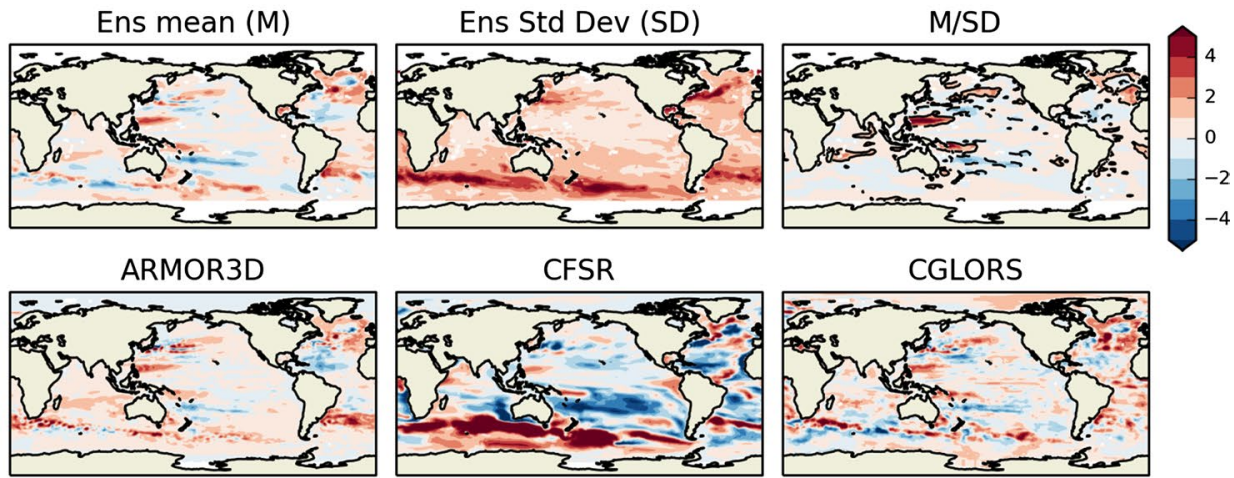

CFSR

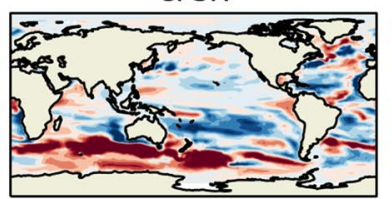

CGLORS
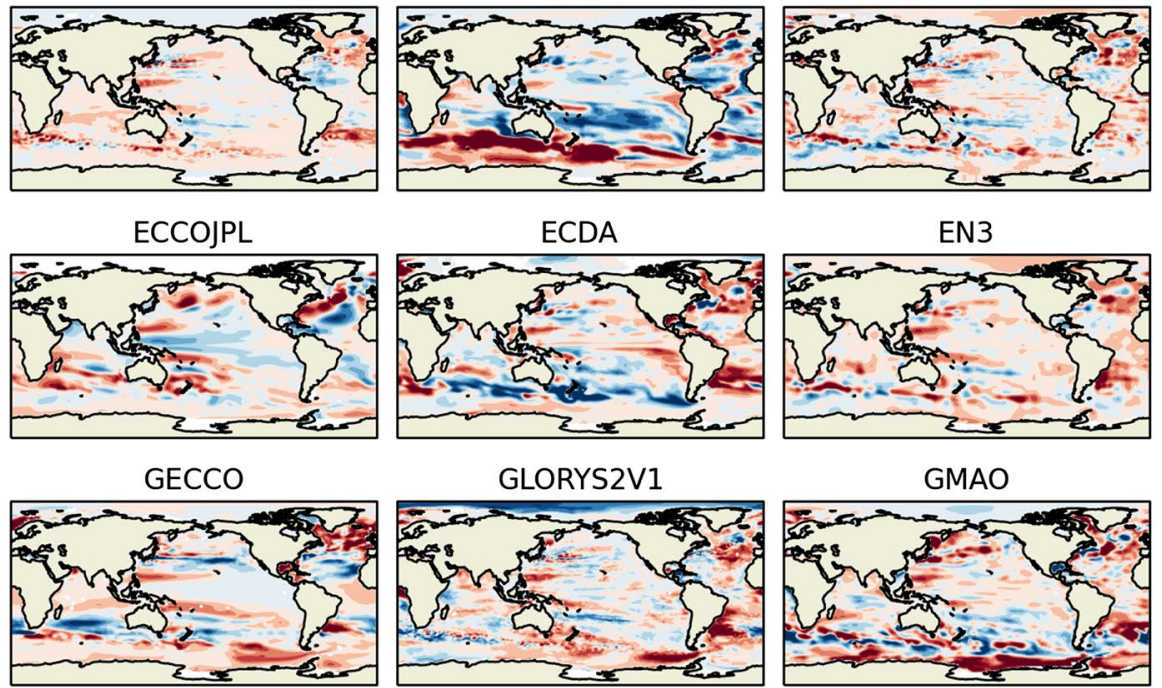

GLORYS2V1
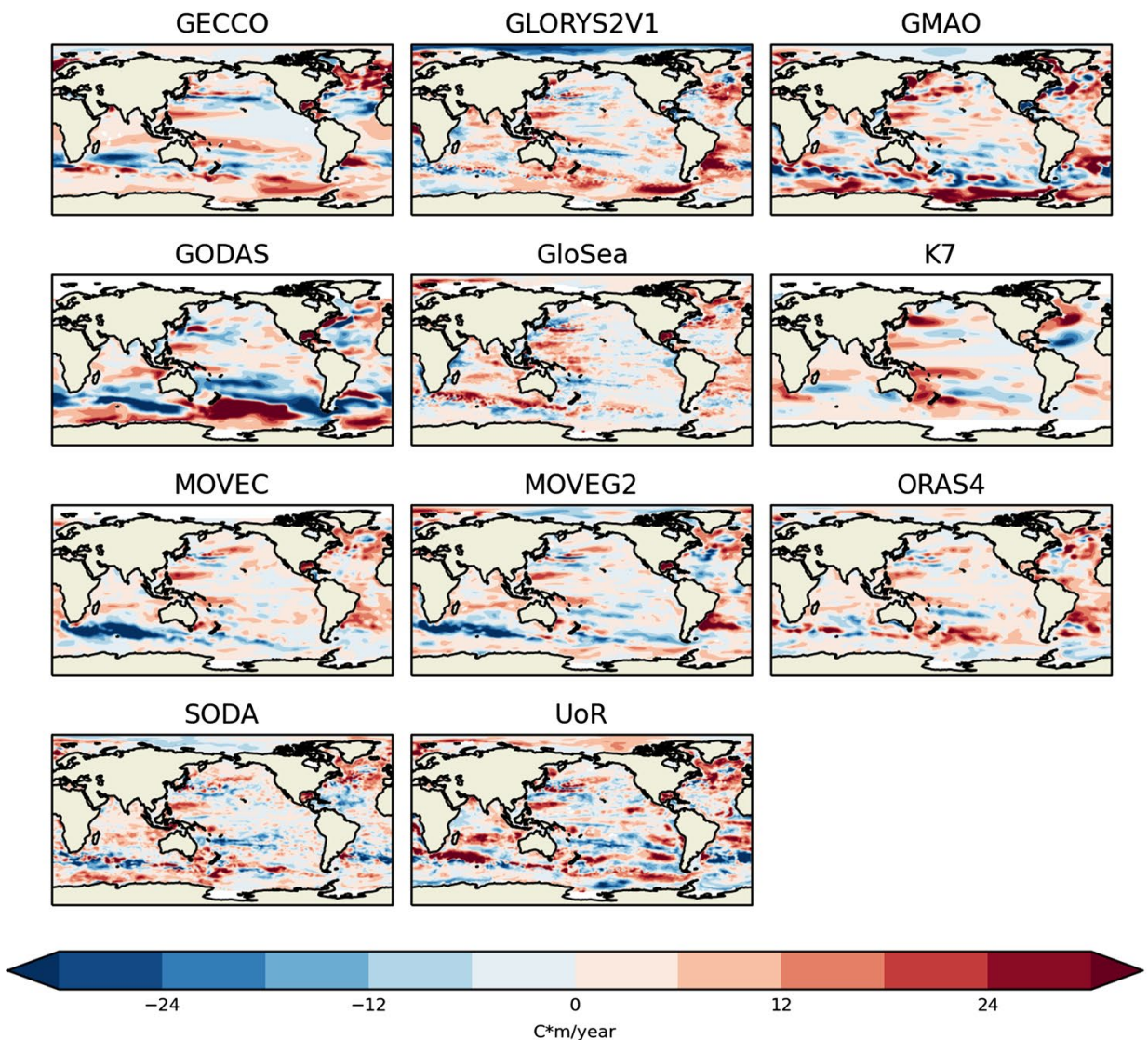

a dynamical ocean model) exhibit warming signals in these regions. Warming of the North Atlantic sub-polar gyre is qualitatively consistent with previous studies that have linked such changes with a reduction in densities and a decline of the AMOC (e.g. Robson et al. 2014; Roberts et al. 2014).

\section{Summary}

We have presented a comparison of the representation of OHC variability and change as estimated by 16 state-ofthe-art ORAs, focusing on five main aspects: (i) the timemean state during 1993-2009; (ii) the amplitude of the 
Fig. 16 Same as Fig. 14, but for the 700-6000 $\mathrm{m}$ layer

Trends in 700-6000m OHC (1997-2009)
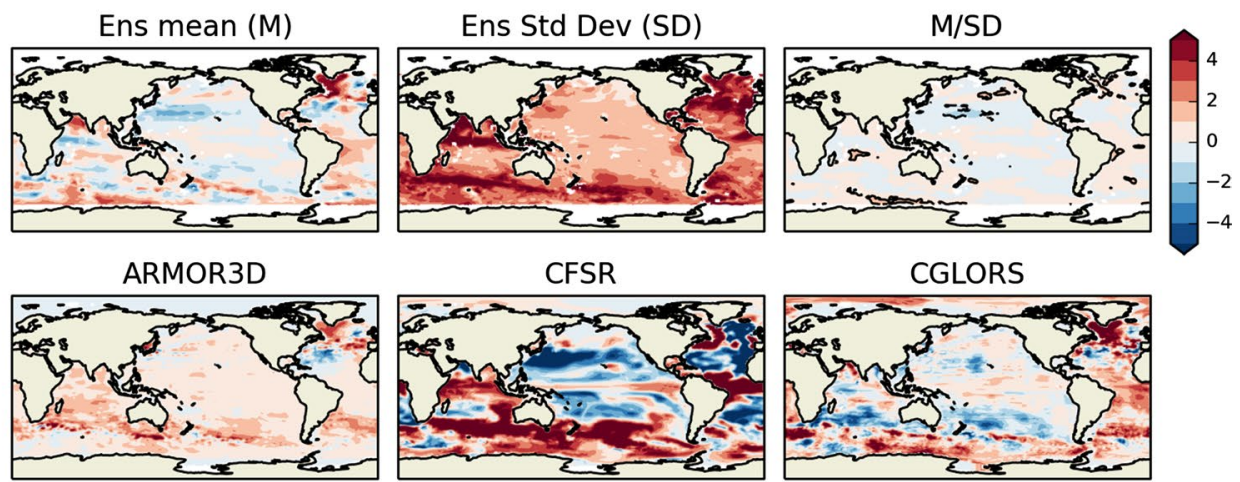

CGLORS

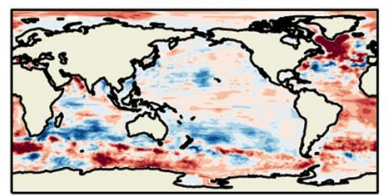

EN3
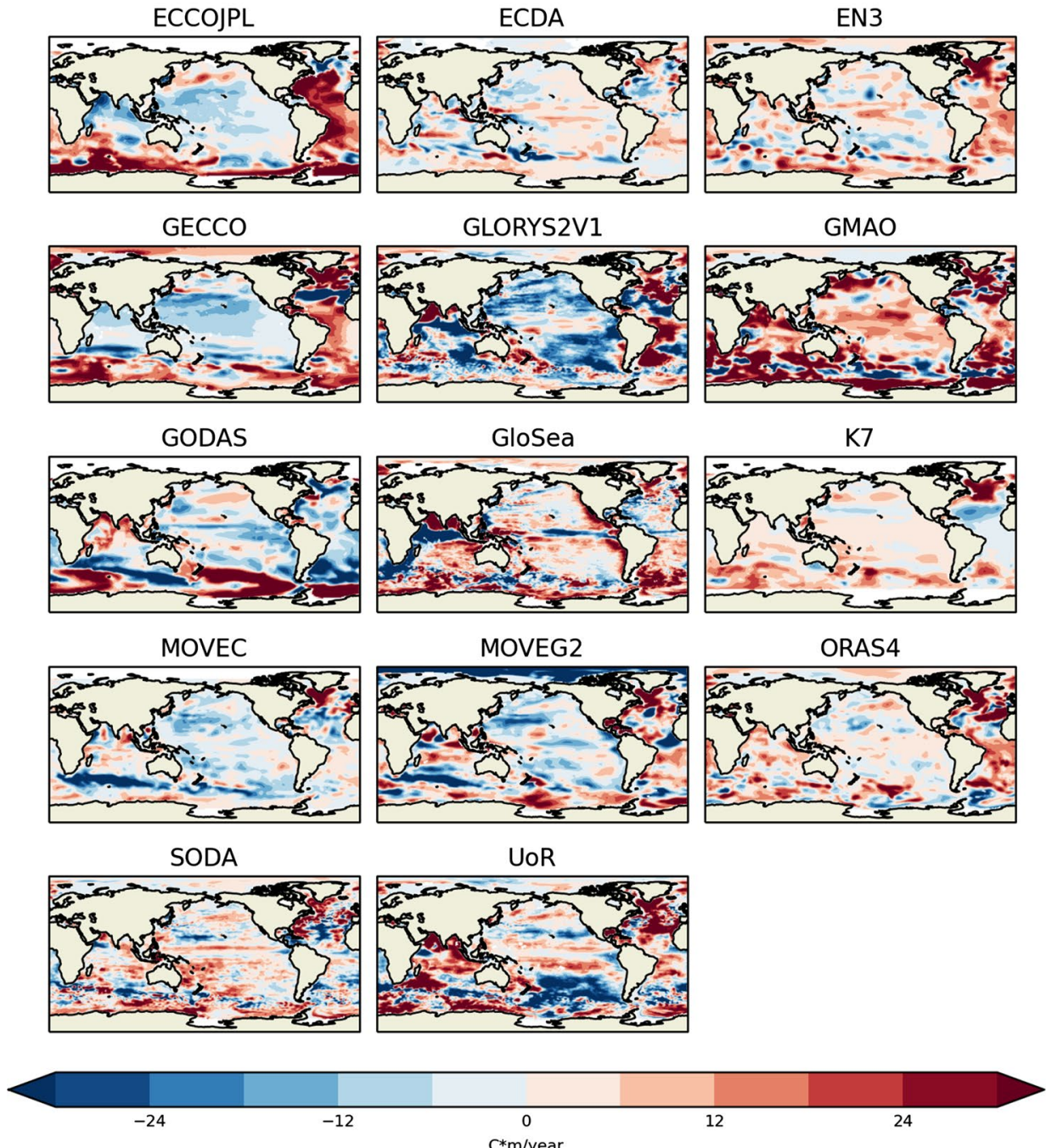

seasonal cycle during 1993-2009; (iii) interannual variability during 1993-2009; (iv) global and hemispheric time series; (v) spatial patterns of change for 1970-2009 and 1997-2009.

The time-mean state and amplitude of the seasonal cycle for the 0-700 layer are generally well-constrained among the ensemble, but regional differences may warrant further investigation. We find that interannual variability for the 0-300 $\mathrm{m}$ can be resolved by the ORA ensemble over the majority of the Indo-Pacific and much of the Atlantic. However, the signal-to-noise ratio rapidly diminishes as one considers deeper layers.

Global time series of $\mathrm{OHC}$ show similar rates of change and ensemble spread to previous studies based only on 
statistical estimates. Comparison of the hemispheric $\mathrm{OHC}$ time series illustrates that the majority of the spread among analyses originates in the Southern Hemisphere. Several ORAs, including those that do not include an OGCM are in qualitative agreement about an increase in ocean heat uptake below $300 \mathrm{~m}$ from the mid 1990s or early 2000s. However, a number appear to suffer from large initialization shock and/or drifts in the deep ocean (where this is little observational constraint on the OGCM solution) so caution should be taken when using such products to estimate the global ocean heat inventory.

Spatial patterns of OHC change for the 0-300 m layer over the period 1970-2009 show large areas of agreement (ensemble mean trend $>$ standard deviation of trends), based on the four analyses included here. While this area is reduced for the 300-700 m layer there remains some agreement on large-scale regions of warming in the Atlantic, Pacific and Southern Oceans. For the 700-6000 m layer only isolated regions of the Southern Ocean and central Atlantic show trends that are resolved by the ensemble spread.

The spatial trends of OHC for the 1997-2009 period generally show large areas of agreement for the $0-300 \mathrm{~m}$, with the Pacific characterized by an east-west dipole. At deeper levels there is little or no agreement among the ensemble. However, the ensemble mean trends for the 700-6000 m layer show the largest warming trends in the North Atlantic sub-polar gyre, north Indian Ocean and Southern Ocean.

Acknowledgments We would like to thank two anonymous reviewers for providing helpful comments on an earlier version of this manuscript. This work is a result of collaboration among the CLIVAR Global Synthesis and Observations Panel and the GODAE Ocean View communities. This work was partly funded by the Joint UK DECC/Defra Met Office Hadley Centre Climate Programme (GA01101) and represents a Met Office contribution to the Natural Environment Research Council DEEP-C project NE/K005480/1.

\section{Compliance with ethical standards}

Conflict of interest The authors declare no conflicts of interest. All authors have given consent to the submission.

Open Access This article is distributed under the terms of the Creative Commons Attribution 4.0 International License (http://creativecommons.org/licenses/by/4.0/), which permits unrestricted use, distribution, and reproduction in any medium, provided you give appropriate credit to the original author(s) and the source, provide a link to the Creative Commons license, and indicate if changes were made.

\section{References}

Abraham JP et al (2013) Monitoring systems of global ocean heat content and the implications for climate change, a review. Rev Geophys. doi: $10.1002 / \mathrm{rog} .20022$

Allan RP et al (2014) Changes in global net radiative imbalance 1985-2012. Geophys Res Lett 41:5588-5597. doi:10.1002/201 4GL060962
Balmaseda $\mathrm{M}$ et al (2010) Initialization for seasonal and decadal forecasts. In: Hall J, Harrison DE Stammer D (eds) Proceedings of OceanObs'09: sustained ocean observations and information for society, vol 2, Venice, Italy, 21-25 September 2009, ESA Publication WPP-306. doi:10.5270/OceanObs09.cwp.02

Balmaseda MA, Mogensen K, Weaver AT (2013a) Evaluation of the ECMWF ocean reanalysis system ORAS4. Q J R Meteorol Soc 139:1132-1161

Balmaseda MA, Trenberth KE, Källén E (2013b) Distinctive climate signals in reanalysis of global ocean heat content. Geophys Res Lett 40:1754-1759. doi:10.1002/grl.50382

Balmaseda MA et al (2015) The Ocean Reanalyses Intercomparison Project (ORA-IP). J Oper Oceanogr 7:81-99

Behringer DW (2007) The global ocean data assimilation system at NCEP. Preprints, 11th Symposium on integrated observing and assimilation systems for atmosphere, oceans, and land surface, San Antonio, TX, Amer. Meteor. Soc., 3.3. https://ams.confex. com/ams/87ANNUAL/webprogram/Paper119541.html

Blockley EW et al (2014) Recent development of the Met Office operational ocean forecasting system: an overview and assessment of the new Global FOAM forecasts. Geosci Model Dev 7:2613-2638. doi:10.5194/gmd-7-2613-2014

Buchard $\mathrm{H}$ et al (2008) Observational and numerical modeling methods for quantifying coastal ocean turbulence and mixing. Prog Oceanogr 76(4):399-442

Carton JA, Giese BS (2008) A reanalysis of ocean climate using simple ocean data assimilation (SODA). Mon Weather Rev 136:2999-3017. doi:10.1175/2007MWR1978.1

Carton JA, Santorelli A (2008) Global decadal upper-ocean heat content as viewed in nine analyses. J Clim 21:6015-6035

Chang Y-S, Zhang S, Rosati A, Delworth TL, Stern WF (2013) An assessment of oceanic variability for 1960-2010 from the GFDL ensemble coupled data assimilation. Clim Dyn 40(3-4):775803. doi:10.1007/s00382-012-1412-2

Chen X, Tung K-K (2014) Varying planetary heat sink led to globalwarming slowdown and acceleration. Science 345:897-903

Cheng L, Zhu J (2014) Artifacts in variations of ocean heat content induced by the observation system changes. Geophys Res Lett 41:7276-7283. doi:10.1002/2014GL061881

Church JA et al (2011) Revisiting the Earth's sea-level and energy budgets from 1961 to 2008. Geophys Res Lett 38:L18601. doi:1 0.1029/2011GL048794

Desbruyères DG et al (2014) Full-depth temperature trends in the northeastern Atlantic through the early 21 st century. Geophys Res Lett 41:7971-7979. doi:10.1002/2014GL061844

Drijfhout SS, Blaker AT, Josey SA, Nurser AJG, Sinha B, Balmaseda MA (2014) Surface warming hiatus caused by increased heat uptake across multiple ocean basins. Geophys Res Lett 41:78687874. doi:10.1002/2014GL061456

Dunstone NJ, Smith DM (2010) Impact of atmosphere and sub-surface ocean data on decadal climate prediction. Geophys Res Lett 37:L02709. doi:10.1029/2009GL041609

England MH et al (2014) Recent intensification of wind-driven circulation in the pacific and the ongoing warming hiatus. Nat Clim Change 4:222-227

Ferry N et al (2012) GLORYS2V1 global ocean reanalysis of the altimetric era (1993-2009) at meso scale. Mercat Ocean Q Newsl 44:28-39. http://www.mercator-ocean.fr/content/download/1625/12971/version/1/file/GLORYS2V1-newsletter44.pdf

Fujii Y et al (2009) Coupled climate simulation by constraining ocean fields in a coupled model with ocean data. J Clim 22:5541-5557

Fujii Y, Tsujino H, Toyoda T, Nakano H (2015) Enhancement of the southward return flow of the Atlantic Meridional Overturning Circulation by data assimilation and its influence in an assimilative ocean simulation forced by CORE-II atmospheric forcing. Clim Dyn. doi:10.1007/s00382-015-2780-1 
Fukumori I (2002) A partitioned Kalman filter and smoother. Mon Weather Rev 130:1370-1383

Guinehut S, Dhomps A-L, Larnicol G, Le Traon P-Y (2012) High resolution 3D temperature and salinity fields derived from in situ and satellite observations. Ocean Sci 8:845-857. doi:10.5194/ os-8-845-2012

Haines K et al (2011) An ocean modelling and assimilation guide to using GOCE geoid products. Ocean Sci 7:151-164. doi:10.5194/ os-7-151-2011

Haines K, Valdivieso M, Zuo H, Stepanov VN (2012) Transports and budgets in a $1 / 4^{\circ}$ global ocean reanalysis $1989-2010$. Ocean Sci 8:333-344. doi:10.5194/os-8-333-2012.002/qj.2063

Haines K, Stepanov VN, Valdivieso M, Zuo H (2013) Atlantic meridional heat transports in two ocean reanalyses evaluated against the RAPID array. Geophys Res Lett 40:343-348. doi:10.1029/ 2012GL054581

Hanawa K, Talley LD (2001) Mode waters. In: Siedler G, Church J (eds) Ocean circulation and climate. International geophysics series. Academic Press, New York, pp 373-386

Hawkins E, Edwards T, McNeall D (2014) Pause for thought. Nat Clim Change 4:154-156

Ingleby B, Huddleston M (2007) Quality control of ocean temperature and salinity profiles-historical and real-time data. J Mar Syst 65:158-175. doi:10.1016/j.jmarsys.2005.11.019

Köhl A (2015) Evaluation of the GECCO2 ocean synthesis: transports of volume, heat and freshwater in the Atlantic. Q J R Meteorol Soc 141:166-181. doi:10.1002/qj.2347

Kuhlbrodt T, Gregory JM (2012) Ocean heat uptake and its consequences for the magnitude of sea level rise and climate change. Geophys Res Lett 39:L18608. doi:10.1029/2012GL052952

Lea DJ, Martin MJ, Oke PR (2014) Demonstrating the complementarity of observations in an operational ocean forecasting system. Q J R Meteorol Soc 140:2037-2049. doi:10.1002/qj.2281

Lee $\mathrm{T}$ et al (2009) Ocean state estimation for climate research. Oceanography $22: 160-167$

Lee $\mathrm{T}$ et al (2013) Evaluation of CMIP3 and CMIP5 wind stress climatology using satellite measurements and atmospheric reanalysis products. J Clim 26:5810-5826. doi:10.1175/ JCLI-D-12-00591.1

Levitus S et al (2012) World ocean heat content and thermosteric sea level change (0-2000 m), 1955-2010. Geophys Res Lett 39:L10603. doi:10.1029/2012GL051106

Loeb NG et al (2012) Observed changes in top-of-the-atmosphere radiation and upper-ocean heating consistent within uncertainty. Nat Geosci 5:110-113. doi:10.1038/NGEO1375

Lyman J, Johnson GC (2014) Estimating global ocean heat content changes in the upper $1800 \mathrm{~m}$ since 1950 and the influence of climatology choice. J Clim 27:1946-1958. doi:10.1175/ JCLI-D-12-00752.1

Lyman JM et al (2010) Robust warming of the global upper ocean. Nature 465:334-337. doi:10.1038/nature09043

Marshall J, Schott F (1999) Open-ocean convection: observations, theory, and models. Rev Geophys 37(1):1-64

Masuda S et al (2010) Simulated rapid warming of abyssal North Pacific waters. Science 329:319-322. doi:10.1126/ science. 1188703

Meehl GA et al (2011) Model-based evidence of deep-ocean heat uptake during surface-temperature hiatus periods. Nat Clim Change 1:360-364

Mogensen K, Balmaseda MA, Weaver AT (2012) The NEMOVAR ocean data assimilation system as implemented in the ECMWF ocean analysis for system 4. Tech memo 668. ECMWF, Reading, UK

Mulet S et al (2012) A new estimate of the global 3D geostrophic ocean circulation based on satellite data and in situ measurements. Deep Sea Res II 77-80:70-81. doi:10.1016/j. dsr2.2012.04.012

Palmer M et al (2010) Future observations for monitoring global ocean heat content. In: Hall J, Harrison DE, Stammer D (eds) Proceedings of OceanObs'09: sustained ocean observations and information for society, vol 2, Venice, Italy, 21-25 September 2009, ESA Publication WPP-306. doi:10.5270/OceanObs09. cwp.68

Palmer MD, McNeall DJ (2014) Internal variability of Earth's energy budget simulated by CMIP5 climate models. Environ Res Lett. doi:10.1088/1748-9326/9/3/034016

Palmer MD, McNeall DJ, Dunstone NJ (2011) Importance of the deep ocean for estimating decadal changes in Earth's radiation balance. Geophys Res Lett. doi:10.1029/2011GL047835

Pohlmann HD et al (2013) Predictability of the mid-latitude Atlantic meridional overturning circulation in a multi-model system. Clim Dyn 41:775-785. doi:10.1007/s00382-013-1663-6

Purkey SG, Johnson GC (2010) Warming of global abyssal and deep Southern Ocean waters Between the 1990s and 2000s: contributions to global heat and sea level rise budgets. J Clim 23:63366351. doi:10.1175/2010JCLI3682.1

Rienecker $M$ et al (2008) The GEOS-5 data assimilation systemdocumentation of versions 5.0.1, 5.1.0, and 5.2.0. NASA/ TM-2008-104606, vol 27

Rienecker M et al (2010) Synthesis and assimilation systems-essential adjuncts to the global ocean observing system. In: Hall J, Harrison DE, Stammer D (eds) Proceedings of OceanObs'09: sustained ocean observations and information for society, vol 1, Venice, Italy, 21-25 September 2009, ESA Publication WPP306. doi:10.5270/OceanObs09.pp.31

Rhein M et al (2013) Observations: ocean. In: Climate change 2013: the physical science basis. In: Stocker TF, Qin D, Plattner G-K, Tignor M, Allen SK, Boschung J, Nauels A, Xia Y, Bex V, Midgley PM (eds) Contribution of working group I to the fifth assessment report of the intergovernmental panel on climate change. Cambridge University Press, Cambridge, United Kingdom and New York, NY, USA

Roberts CD et al (2013) Atmosphere drives recent interannual variability of the Atlantic meridional overturning circulation at $26.5^{\circ} \mathrm{N}$. Geophys Res Lett 40:5164-5170. doi:10.1002/grl.50930

Roberts CD, Jackson LJ, McNeall D (2014) Is the 2004-2012 reduction of the Atlantic meridional overturning circulation significant? Geophys Res Lett 41:3204-3210. doi:10.1002/201 4GL059473

Robson J, Hodson D, Hawkins E, Sutton R (2014) Atlantic overturning in decline? Nat Geosci. doi:10.1038/ngeo2050

Roemmich D et al (2009) The Argo Program: observing the global ocean with profiling floats. Oceanography 22:34-43. doi:10.5670/ oceanog.2009.36

Roemmich D, Gould WJ, Gilson J (2012) 135 years of global ocean warming between the Challenger expedition and the Argo Programme. Nat Clim Change 2:425-428. doi:10.1038/ nclimate1461

Roemmich D et al (2015) Unabated planetary warming and its ocean structure since 2006. Nat Clim Change. doi:10.1038/ nclimate 2514

Saha $\mathrm{S}$ et al (2010) The NCEP climate forecast system reanalysis. Bull Am Meteorol Soc 91:1015-1057

Smith D et al (2015) Earth's energy imbalance since 1960 in observations and CMIP5 models. Geophys Res Lett. doi:10.1002/20 14GL062669

Storto A, Dobricic S, Masina S, Di Pietro P (2011) Assimilating along-track altimetric observations through local hydrostatic adjustments in a global ocean reanalysis system. Mon Weather Rev 139:738-754 
Stott PA, Forest CE (2007) Ensemble climate predictions using climate models and observational constraints. Philos Trans R Soc 365:2029-2052

Toyoda $\mathrm{T}$ et al (2013) Improved analysis of the seasonal-interannual fieldsby a global ocean data assimilation system. Theor Appl Mech Japan 61:31-48. doi:10.11345/nctam.61.31

Toyoda $T$ et al (2015) Intercomparison and validation of the mixed layer depth fields of global ocean syntheses/reanalyses. Clim Dyn. doi:10.1007/s00382-015-2637-7

Trenberth KE, Fasullo JT (2013) An apparent hiatus in global warming? Earth's Future 1:19-32. doi:10.1002/2013EF000165

Trenberth KE, Fasullo JT, Balmaseda MA (2014) Earth's energy imbalance. J Clim 27:3129-3144. doi:10.1175/JCLI-D-13-00294

Valdivieso $M$ et al (2015) An assessment of air-sea heat fluxes from ocean and coupled reanalyses. Clim Dyn (submitted)
Wijffels SE et al (2008) Changing expendable bathythermograph fallrates and their Impact on estimates of thermosteric sea level rise. J Clim 21:5657-5672

Xue $\mathrm{Y}$ et al (2011) An assessment of oceanic variability in the NCEP climate forecast system reanalysis. Clim Dyn 37:2511-2539

Xue Y et al (2012) A comparative analysis of upper ocean heat content variability from an ensemble of operational ocean reanalyses. J Clim 25:6905-6929

Zhang S et al (2007) System design and evaluation of coupled ensemble data assimilation for global oceanic climate studies. Mon Weather Rev. doi:10.1175/MWR3466.1 